4-2002

\title{
Cellular Array Morphology During Directional Solidification
}

\author{
Surendra N. Tewari \\ Cleveland State University

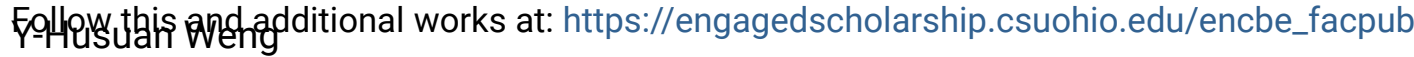

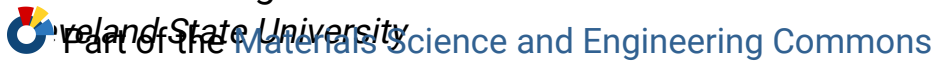 \\ G. H.w. Bing access to this work benefit you? Let us know!

\section{Biblibd is Gex'Begtatemregt}

Copyright 2002 ASM International. This paper was published in Metallurgical and Materials

Pransactions. A: P.hysical Metallurgy and Materials Science, Vol. 33, Issue 4, pp. 1229-1243 and is made available as an electronic reprint with the permission of ASM International. One print or electronic copy may be made for personal use only. Systematic or multiple reproduction, distribution to multiple locations via electronic or other means, duplications of any material in this paper for a fee or for commercial purposes, or modification of the content of this paper are prohibited.

Available on publisher's site at: http://www.asminternational.org/portal/site/www/AsmStore/ ProductDetails/?vgnextoid=a6a3c777b3426210VgnVCM100000621e010aRCRD.

\section{Original Citation}

Tewari, S.N., Weng, Y.H.S., Ding, G.L., \& Trivedi, R. (2002). Cellular Array Morphology During Directional Solidification. Metallurgical and Materials Transactions A: Physical Metallurgy and Materials Science 33, 1229-1243.

\section{Repository Citation}

Tewari, Surendra N.; Weng, Y-Husuan; Ding, G. L.; and Trivedi, R., "Cellular Array Morphology During Directional Solidification" (2002). Chemical \& Biomedical Engineering Faculty Publications. 3.

https://engagedscholarship.csuohio.edu/encbe_facpub/3

This Article is brought to you for free and open access by the Chemical \& Biomedical Engineering Department at EngagedScholarship@CSU. It has been accepted for inclusion in Chemical \& Biomedical Engineering Faculty Publications by an authorized administrator of EngagedScholarship@CSU. For more information, please contact library.es@csuohio.edu. 


\title{
Cellular Array Morphology during Directional Solidification
}

\author{
S.N. TEWARI, Y-HUSUAN WENG, G.L. DING, and R. TRIVEDI
}

Cellular array morphology has been examined in the shallow cell, deep cell, and cell-to-dendrite transition regime in $\mathrm{Pb}-2.2 \mathrm{wt}$ pct $\mathrm{Sb}$ and $\mathrm{Al}-4.1 \mathrm{wt}$ pct $\mathrm{Cu}$ alloy single-crystal samples that were directionally solidified along [100]. Statistical analysis of the cellular spacing distribution on transverse sections has been carried out using minimum spanning tree (MST), Voronoi polygons, radial distribution factor, and fast Fourier transform (FFT) techniques. The frequency distribution of the number of nearest neighbors and the MST parameters suggest that the arrangement of cells may be visualized as a hexagonal tessellation with superimposed $50 \mathrm{pct}$ random noise. However, the power spectrum of the Fourier transform of the cell centers shows a diffused single-ring pattern that does not agree with the power spectrum from the hexagonal tessellation having a 50 pct superimposed random (uniformly distributed or Gaussian) noise. The radial distribution factor obtained from the cells is similar to that of liquids. An overall steady-state distribution in terms of the mean primary spacing is achieved after directional solidification of about three mushy-zone lengths. However, the process of nearest-neighbor interaction continues throughout directional solidification, as indicated by about $14 \mathrm{pct}$ of the cells undergoing submerging in the shallow cell regime or by an increasing first and second nearest-neighbor ordering along the growth direction for the cells at the cell-to-dendrite transition. The nature of cell distribution in the Al-Cu alloy appears to be the same as that in the $\mathrm{Pb}$ $\mathrm{Sb}$. The ratio between the upper and lower limits of the primary spacing, as defined by the largest and the smallest $10 \mathrm{pct}$ of the population, respectively, is constant: $1.43 \pm 0.11$. It does not depend upon the solidification processing conditions.

\section{INTRODUCTION}

A HOMOGENEOUS distribution of primary spacing of cells and dendrites is required to achieve a uniform distribution of mechanical properties in castings. Dependence of primary spacing on solidification processing parameters has been extensively investigated. During directional solidification of binary alloys in a positive thermal gradient, shallow cells, deep cells, and dendrites are observed with increasing growth speed. ${ }^{[1]}$ In the shallow cell regime, the primary spacing decreases with increasing growth speed. It begins to increase during the deep cell formation and rises sharply after the cell-to-dendrite transition. After reaching a maximum, the spacing continues to decrease with increasing growth speed for dendritic microstructures. The primary spacing is generally measured as $\sqrt{A / n}$, where $n$ is the number of cells/dendrites in an area, $A$. This analysis, inherently, assumes a square distribution. However, a dominant sixfold symmetry has been observed in the frequency distribution of the number of nearest neighbors for cellular microstructures. ${ }^{[2]}$ An analysis of the nearest-neighbor and higher-order spacing distribution of cells and dendrites for $\mathrm{Pb}-\mathrm{Sb}$ alloys ${ }^{[3]}$ is in agreement with a dominant hexagonal pattern. Minimum spanning trees (MSTs), which are created by joining the cell centers, in directionally solidified $\mathrm{Pb}-\mathrm{Tl}^{[2]}$ and succinonitrile-acetone ${ }^{[4]}$ alloys yield patterns that are similar to

S.N. TEWARI, Professor, and Y-HUSUAN WENG, Graduate Student, are with the Chemical Engineering Department, Cleveland State University, Cleveland, OH 44115. Contact e-mail: s.tewari@csuohio.edu G.L. DING, formerly Research Associate, Chemical Engineering Department, Cleveland State University, is with the Department of Computing Maths and Statistics, Grand Prairie Regional College, Grand Prairie, Canada T8V 4C4. R. TRIVEDI, Professor, is with the Department of Materials Science and Engineering, Iowa State University, Ames, IA 50011.

Manuscript submitted July 23, 2001. those obtained from a hexagonal lattice with superimposed Gaussian noise. It has, therefore, been suggested that the distribution of cells can be visualized as a hexagonal tessellation with some superimposed random noise. However, all these observations are based on polycrystalline samples where the primary spacing distribution may have considerable scatter associated with grain multiplicity and grain boundaries.

The purpose of this study was to examine the cellular arrays in $\mathrm{Pb}-2.2 \mathrm{wt}$ pct $\mathrm{Sb}$ and $\mathrm{Al}-4.1$ wt pct $\mathrm{Cu}$ alloy singlecrystal samples directionally solidified along [100] and determine the solidification length necessary to establish steady-state array morphologies. Solute enrichment of the melt due to solidification would decrease the melt density for the $\mathrm{Pb}-\mathrm{Sb}$ alloy and would increase it for the $\mathrm{Al}-\mathrm{Cu}$ alloy. Therefore, a density inversion occurs in the melt in the mushy zone and also at the cellular array tips during directional solidification of the $\mathrm{Pb}-\mathrm{Sb}$ alloy. This causes extensive convection and produces macrosegregation along the growth direction. ${ }^{[5]}$ However, the radial macrosegregation is usually minimal (if the growth conditions are not susceptible to the formation of "channel segregates"), and a uniform cell/dendrite distribution across the entire sample cross section is achieved. During directional solidification of the $\mathrm{Al}-\mathrm{Cu}$ alloy in a positive thermal gradient, no convection is expected. However, presence of any radial thermal gradient causes convection and may result in radial macrosegregation $^{[6]}$ and a nonuniform cell/dendrite distribution across the specimen cross section. The growth conditions selected in this study did not produce any channel segregates in the $\mathrm{Pb}-\mathrm{Sb}$ alloy. In addition "cellular steepling" was avoided for the Al-Cu alloy. Therefore, the entire, sample cross-section area ( 0.6 to $0.7 \mathrm{~cm}$ diameter) has been included in carrying out the statistical analyses. 


\section{EXPERIMENTAL PROCEDURE}

\section{A. Alloy Preparation and Directional Solidification}

About 24- to 30-cm-long $\mathrm{Pb}-\mathrm{Sb}$ feed stock samples were obtained by induction melting a charge $(\mathrm{Pb} 99.99$ wt pct purity and Sb 99.999 wt pet purity) under an ultra-high purity argon atmosphere in a graphite crucible and pushing the melt into evacuated quartz tubes $(0.6-\mathrm{cm}$ inner diameter (ID)) with the help of argon pressure. The cast $\mathrm{Pb}-2.2 \mathrm{wt}$ pct $\mathrm{Sb}$ feedstock cylinders were extracted and placed into a quartz directional-solidification ampoule $(0.7-\mathrm{cm} \mathrm{ID,} 61-\mathrm{cm}$ long) on top of a pure lead, single-crystal seed. The [100] crystallographic orientation of the seed was parallel to the axis of the ampoule. After remelting about $1 \mathrm{~cm}$ of the seed, the sample was directionally solidified in ultra-high purity argon at $10 \mu \mathrm{m} \mathrm{s}^{-1}$ to obtain about 15-cm-long seed. A 4.5$\mathrm{cm}$-long piece from this single crystal was used as a seed for all the $\mathrm{Pb}-2.2 \mathrm{wt}$ pct $\mathrm{Sb}$ specimens directionally solidified in this study. A thermal gradient of $164 \mathrm{~K} \mathrm{~cm}^{-1}$ was used with growth speeds of $1.5,1.8,2,2.5,4,5$, and $10 \mu \mathrm{m}$ $\mathrm{s}^{-1}$ to obtain arrays with shallow cells, deep cells, cell-todendrite transition, and dendrites. The initial melt-column length at the onset of directional solidification was about 18 $\mathrm{cm}$. The samples were quenched by spraying water on the ampoule surface after directional solidification for a length varying from 1 to $10 \mathrm{~cm}$. For example, one set was quenched after $10 \mathrm{~cm}$ of directional solidification, and another set was quenched after solidification distance of only $3 \mathrm{~cm}$. Al-4.1 wt pct $\mathrm{Cu}$ single-crystal samples were directionally solidified at $10 \mu \mathrm{m} \mathrm{s}^{-1}$ in an alumina ampoule under a flowing argon atmosphere at $110 \mathrm{~K} \mathrm{~cm}^{-1}$. A pure aluminum [100] crystal was used as seed for these samples.

\section{B. Metallography}

Longitudinal (parallel to the alloy growth direction) and transverse microstructures were observed by standard polishing and optical metallography techniques. An etchant made up of 60-mL acetic acid and 40-mL hydrogen peroxide $(30 \mathrm{pct})$ was used to provide a suitable contrast for electronic image capture for the $\mathrm{Pb}-\mathrm{Sb}$ alloy. The $\mathrm{Al}-\mathrm{Cu}$ alloy was etched by Keller's reagent. A montage of the microstructures recorded at 50 times magnification was created in order to obtain a high-resolution image of the entire sample cross section.

\section{Tools for Statistical Analysis of Ordering in the Microstructure}

\section{Center of mass}

In order to carry out the statistical analysis of the extent of ordering in the directionally solidified microstructures, the center of mass of the individual cells/dendrites was chosen to be the characteristic representation. Centers of mass were identified in the following two manners. In the first method, the geometrical center of each feature was manually located and electronically recorded as a table of $(x, y)$ coordinates. In the second method, a computer-aided, pattern-recognition technique was utilized. Each image was reduced to a 2-bit image, i.e., an intensity threshold was chosen, and all the pixels with intensity greater than that threshold were assigned as white color (represented as 255 in the gray scale table), and all the other pixels were assigned as black color
(0 in the gray scale table). An erosion filter was applied to these images to open up any interconnected features. The image analysis software, HLIMAGE 97 (Data Translation, Marlboro, MA), ${ }^{[7]}$ was used to identify the individual features ("blobs"), locate their centers of mass, and create the corresponding $(x, y)$ coordinate table. We believe that the first method should provide more reliable results because it involves carefully locating the center of each cell/dendrite after magnifying its image. This procedure becomes especially important when a particular feature is not symmetric with respect to its center of mass, as is the case with the dendritic morphologies. However, because of the relatively large number of features (1000 to 6000) being counted for each growth condition, the statistical results from the two techniques were nearly the same. We will, therefore, present here only those results, which are based on the analysis of the manually identified centers of mass.

\section{Gauss amplitude fit to the frequency distribution of} nearest and higher-order spacings

The $(x, y)$ coordinates for the centers of mass were used to create the frequency distribution of nearest and higherorder intercellular/dendritic spacings. The spacing data larger than five times the mean nearest-neighbor spacing were ignored in the subsequent Gauss-amplitude peak analysis. A linear background correction and fast Fourier transform (FFT) smoothing was applied to the data and the software, Peakfit (Jandel Scientific, Corte Madera, CA), ${ }^{[8]}$ was used to extract the peaks and their associated parameters. For each peak, the frequency, $F$, is given by, $F=A_{0} \exp$ $\left[-0.5\left(\left(X-A_{1}\right) / A_{2}\right)^{2}\right]$, where $A_{0}$ is the amplitude, $A_{1}$ the center position, and $A_{2}$ the width.

\section{Voronoi tessellation}

Voronoi tessellation is a tiling of space where each tile represents the space closest to a particular point. ${ }^{[9]}$ In this analysis, the points are first triangulated, and then, perpendicular bisectors to the segments joining any two centers are drawn. The smallest convex polygons surrounding each point are, thus, defined, containing all its nearest neighbors. Therefore, the number of sides of a Voronoi polygon reveals the number of neighboring features. We have used this technique to examine the degree of disorder in the distribution of cellular/dendritic features in this study. This technique is similar to the Wigner-Seitz construction that has earlier been used to analyze the frequency distribution of nearest neighbors for cellular microstructures. ${ }^{[2]}$

\section{Minimum spanning tree}

A MST is a connected curve without any closed loop that contains all the centers and for which the sum of the edge weights is minimal. Such a tree represents the shortest total length of the branches in order to connect all the nodes. We have used Prim's algorithm ${ }^{[10]}$ where an arbitrary node is chosen initially as the tree root. The node nearest to the tree is identified and is joined to the tree. This process is repeated until all the points are connected to this MST. Mean of the branch lengths $\left(m^{*}\right)$ and their standard deviation $\left(\sigma^{*}\right)$ can be used to provide a statistical measure of the nearest-neighbor distribution. It was shown by Dussert et al. ${ }^{[11]}$ that the two parameters, $m^{*}$ and $\sigma^{*}$, can be normalized by dividing them by the square root of the average cell surface $\langle S\rangle$ to yield $m$ and $\sigma$, where $m=\frac{m^{*}}{\sqrt{\langle S\rangle}} \frac{N-1}{N}$ and $\sigma=\frac{\sigma^{*}}{\sqrt{\langle S\rangle}} \frac{N-1}{N}$. The 
$m$ vs $\sigma$ plots can be used to compare arrangements with different nearest-neighbor spacings. Using this analysis, Dussert et al. ${ }^{[11]}$ have suggested that the distribution of cells can be visualized as a hexagonal tessellation with superimposed random noise.

\section{Fast Fourier transform}

The FFT of the image containing the cell/dendrite centers has been used to analyze the disorder of the cellular/dendritic arrays in this study. In the FFT of the image, each pixel is a complex number describing the contribution of a sinusoidal function to the original image. The magnitude of the pixel encodes the amplitude of the sinusoid, and the orientation of the complex pixel encodes the phase of the sinusoid. The power spectrum magnitude is usually represented on a log scale, since power can vary dramatically from one frequency to the next. Our FFT images have been transformed such that distance from the center in an FFT image is directly proportional to the frequency, i.e., the intensity (power spectrum magnitude) corresponding to the highest frequency appears closest to the center in the FFT image. However, unlike the previously described MST, Voronoi polygon and peak-fit analyses, where the entire sample cross section was used in the analysis, we have used the largest portion of the image with sides that are powers of two (e.g., $1024 \times 1024$ pixels) for the FFT analysis.

\section{Simulation of cell/dendrite distribution by using} hexagonal array of points

Following the procedure used by Dussert et al., ${ }^{[11]}$ a hexagonal array of points has been used for simulating the cellular/dendritic arrangements. The hexagonal tessellations, that is the $(X, Y)$ coordinate lists, were first created. An increasing amount of random noise was then superimposed on these tessellations by generating two, independent random numbers for the $X$ and $Y$ coordinates and adding these to the original coordinates. Two types of random number generators, one generating uniformly distributed random numbers and the other yielding Gaussian-distributed random numbers, were used. The Voronoi polygon, MST, and FFT techniques have also been used to examine the simulated lattices having increasing amounts of superimposed random noise.

\section{Pair distribution function}

The pair distribution function ${ }^{[12]}$ gives the probability of finding a pair of points a distance apart, relative to the probability expected for a completely random distribution at the same density of points. This ratio, also called the radial distribution factor, is usually plotted as a function of nondimensional radial distance, i.e., the ratio of the radial distance to the mean nearest-neighbor distance. Such a plot for crystalline solids yields distinct lines corresponding to the nearest and higher-order neighboring atoms. Liquids yield a diffused peak for the nearest neighbor and may yield a second diffused peak for the next nearest-neighbor atoms. ${ }^{[12]}$ The cell/dendrite center-point images were used to obtain the radial distribution factor as a function of nondimensionalized distance. As will be shown in section III-B, the cellular morphologies show a behavior very similar to the liquids.

\section{RESULTS}

\section{A. Microstructure}

Figure 1(a) shows the longitudinal microstructure for the $\mathrm{Pb}-2.2$ wt pet $\mathrm{Sb}$ alloy directionally solidified at $1.5 \mu \mathrm{m}$ $\mathrm{s}^{-1}$ at a thermal gradient of $164 \mathrm{~K} \mathrm{~cm}^{-1}$. This sample was directionally solidified with shallow cell morphology for a distance of $10 \mathrm{~cm}$ before being quenched. The symbols " $\mathrm{L}$ " and " $\mathrm{S}$ " in Figure 1(a) indicate the liquid and solid portions at the time of quench. The process of tip splitting is evident in this figure. The cells appear to join, their boundaries disappearing, as a function of increasing distance from the liquid-solid interface. Therefore, true representation of the primary spacing can only be obtained on transverse sections that are close to the interface. The transverse view at a distance of $100 \mu \mathrm{m}$ from the array tips is indicated in Figure 1(b). The darker region located at the bottom-left side of the transverse view is the quenched liquid portion. The dark nodes, dispersed throughout the rest of the transverse view, represent the solute-rich intercellular region. Such dark nodes are not seen in the samples grown at higher growth speeds because the cell joining in these samples occurred only after a distance of at least $300 \mu \mathrm{m}$.

Figure 2 shows the transverse views of several other $\mathrm{Pb}$ $2.2 \mathrm{wt}$ pct $\mathrm{Sb}$ samples examined in this study. All these transverse views represent the cross section at a distance of about $100 \mu \mathrm{m}$ from the quenched liquid-solid interface. Figure 2(a) is near the shallow cell to deep cell transition (growth speed $1.8 \mu \mathrm{m} \mathrm{s}^{-1}$ ). Figure 2(b) represents the deepcell morphology (growth speed $2.5 \mu \mathrm{m} \mathrm{s}^{-1}$ ). Figure 2(c) is at the cell-to-dendrite transition (growth speed $5 \mu \mathrm{m}$ $\mathrm{s}^{-1}$ ), and Figure 2(d) represents the dendritic morphology (growth speed $10 \mu \mathrm{m} \mathrm{s}^{-1}$ ). These figures also contain typical high magnification views in their inset.

Very small features surrounded by larger cross-section features in the cellular microstructures (shown at higher magnification in the inset of Figure 2(a)) are indicative of cell submerging, cells which are lagging their neighbors and are in the process of being eliminated. The extent of cell submerging, i.e., ratio of the number of cells, which are in the process of being eliminated to their total number, decreases with increasing growth speed. For example, this ratio is 0.14 at $1.8 \mu \mathrm{m} \mathrm{s}^{-1}, 0.08$ at $2 \mu \mathrm{m} \mathrm{s}^{-1}, 0.05$ at 2.5 $\mu \mathrm{m} \mathrm{s}^{-1}$, and 0.01 at $4 \mu \mathrm{m} \mathrm{s}^{-1}$. The evidence of tip splitting (dark contrast points enclosed within a cell, marked by an arrow in the inset of Figure 2(b)) is, however, not as frequent on the transverse sections because the process of tip splitting is localized at the very tips of the cellular array and is not likely to be observed on a cross section that is about $100 \mu \mathrm{m}$ away from the tips.

It is interesting that even after a translation of $9 \mathrm{~cm}$, the process of tip splitting and cell submerging continues, and a true steady-state distribution of cells has not been achieved. This is especially true for the shallow cells. This behavior is in agreement with the theoretical predictions by Unger and Brown. ${ }^{[13]}$

Figure 2(c) shows the $\mathrm{Pb}-\mathrm{Sb}$ cell to dendrite transition microstructure at the growth speed of $5 \mu \mathrm{m} \mathrm{s}{ }^{-1}$. Some regions of the sample (marked "A") show unbranched cells while branched dendrites are seen in other regions (marked " $\mathrm{B}$ "). This is expected to cause significant inhomogeneity in the primary spacing distribution. 


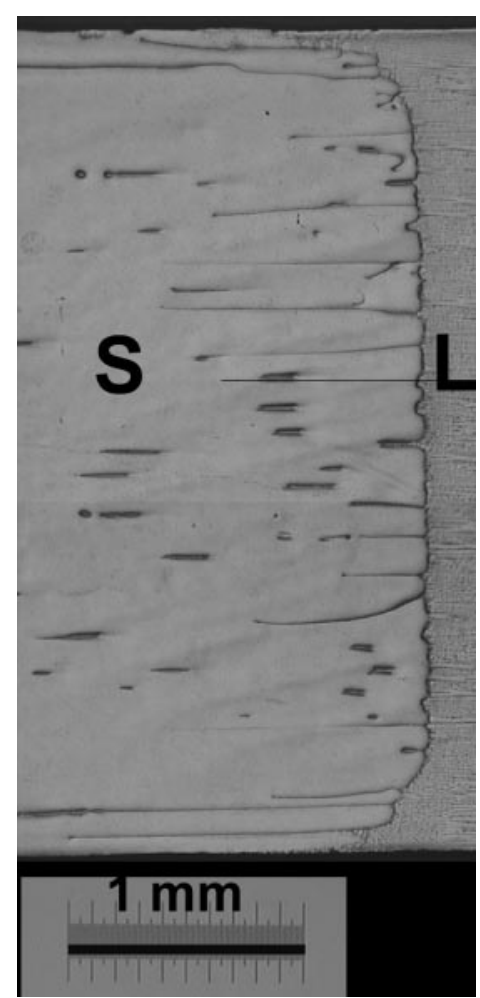

(a)

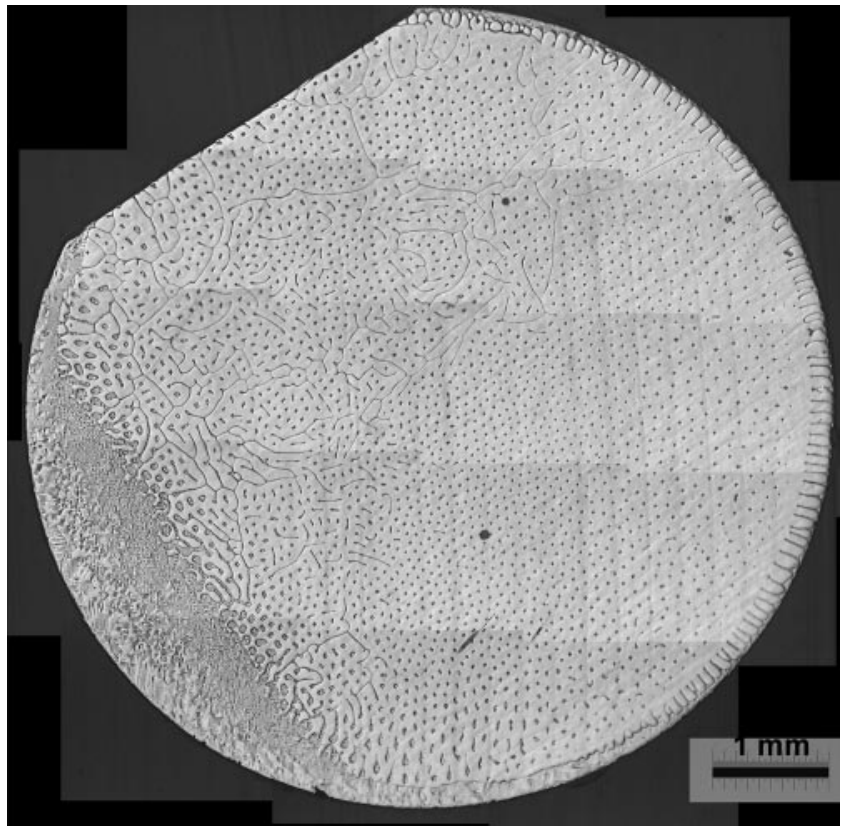

(b)

Fig. 1-Microstructure of the $\mathrm{Pb}-2.2 \mathrm{wt}$ pct Sb alloy single crystal directionally solidified along [100] at $1.5 \mu \mathrm{m} \mathrm{s}^{-1}$ with a thermal gradient of $164 \mathrm{~K}$ $\mathrm{cm}^{-1}$. (a) Longitudinal section near the quenched liquid-solid interface. "L" indicates the quenched liquid and "S" indicates the directionally solidified portion. (b) Transverse section at about $100 \mu \mathrm{m}$ from the quenched interface.

Figure 2(d) shows the $\mathrm{Pb}-\mathrm{Sb}$ alloy transverse microstructure at a higher growth speed of $10 \mu \mathrm{m} \mathrm{s}^{-1}$ where the microstructure is completely dendritic. The distribution of dendrites is not uniform across the entire sample cross section. The image appears to be made up of islands within which the distribution is uniform. However, from island to island, there is significant variation in the dendrite distribution. "Channel-like" regions, in which the dendrites are very sparse, separate the islands. Samples with cellular morphology do not show this behavior (Figures 2(a) through (c)).

As mentioned earlier, buildup of solute in the liquid ahead of the cellular/dendritic array tips creates an unstable density stratification and causes buoyancy-driven convection. If the mushy zone is permeable, especially near the array tips, this convection causes entrainment into the mushy zone and is responsible for creating the channel-like regions described previously. For the cells, the tip radius is much larger, as compared with the dendrites, and the permeability in the vicinity of the tips is negligible. Therefore, convection is constrained in the overlying melt and does not enter into the mushy region. Hence, the arrangement of cells across the entire sample cross section is more uniform, as compared with the dendrites.

Figure 3 shows the transverse microstructure for the two Al-4.1 wt pet $\mathrm{Cu}$ samples grown in the deep cell regime. The first sample was quenched after a translation distance of 3 $\mathrm{cm}$ (Figure 3(a)) and the second after $9 \mathrm{~cm}$ (Figure 3(b)). Since, a translation distance of $3 \mathrm{~cm}$ appears to be sufficient to establish an overall steady-state arrangement of cells across the sample cross section, here, we will present results only for two sets of samples: one grown for $3 \mathrm{~cm}$ and then quenched, and the other grown for 9 to $10 \mathrm{~cm}$ before being quenched. Results from similar experiments on the $\mathrm{Pb}-2.2$ wt pct Sb samples will be described in Section B-2.

\section{B. Steady-State Distribution of Cells}

A detailed statistical analysis, using several techniques described subquently, shows that an overall steady-state distribution of cells in terms of their average primary spacing becoming constant is achieved by directional solidification of $3 \mathrm{~cm}$, which is about three mushy-zone length for the $\mathrm{Al}-\mathrm{Cu}$ alloys. The experimentally determined statistical measures of the cell/dendrite distribution on the transverse sections are summarized in Table I for all the samples examined in this study. The first column lists the sample number, the second lists the growth speed, and the third lists the solidification distance before quenching. The number of features $(N)$ and the corresponding cross-sectional areas $(A)$ for the various samples are listed in columns 4 and 5, respectively. The primary spacing, as determined by $\sqrt{(A / N)}$, is given in column 6 . The three parameters, $A_{0}$ (peak height), $A_{1}$ (peak location), and $A_{2}$ (peak width) describing the Gaussian fit to the frequency distribution of the number of nearest neighbors as determined by the Voronoi polygon analyses are listed in columns 7 through 9 . Columns 10 and 11 list the two measures obtained from the MST analyses: the mean branch length and its standard deviation $\left(m^{*} \pm\right.$ $\left.\sigma^{*}\right)$ and the nondimensionalized mean and its standard deviation $(m \pm \sigma)$. The upper and lower limits of the MST branch-lengths spacing were identified as corresponding to the largest $10 \mathrm{pct}$ and the smallest $10 \mathrm{pct}$ of the population. 


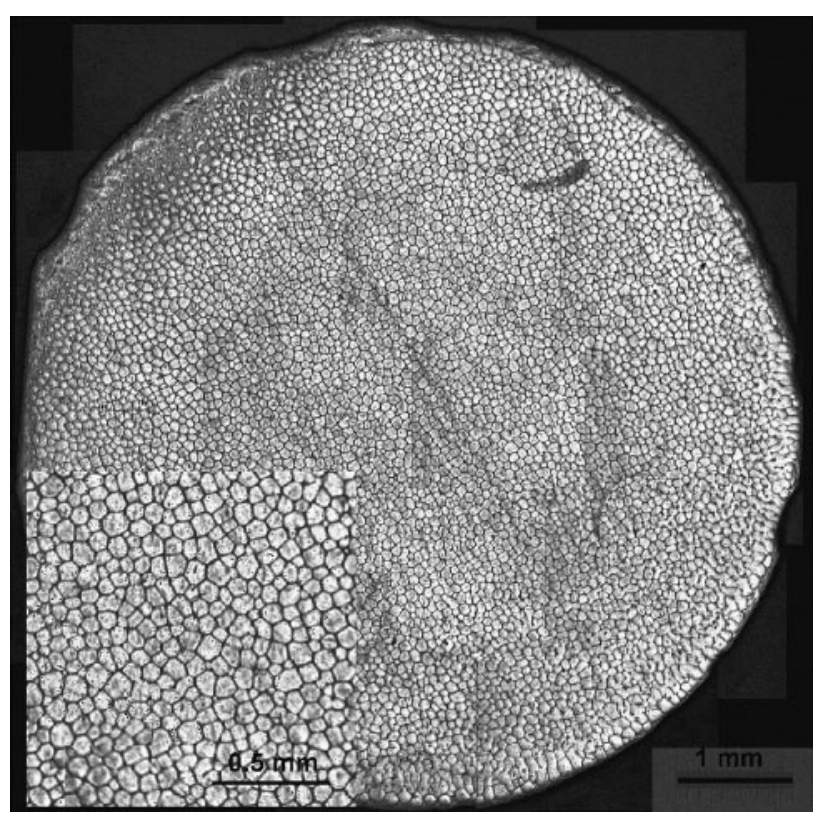

(a)

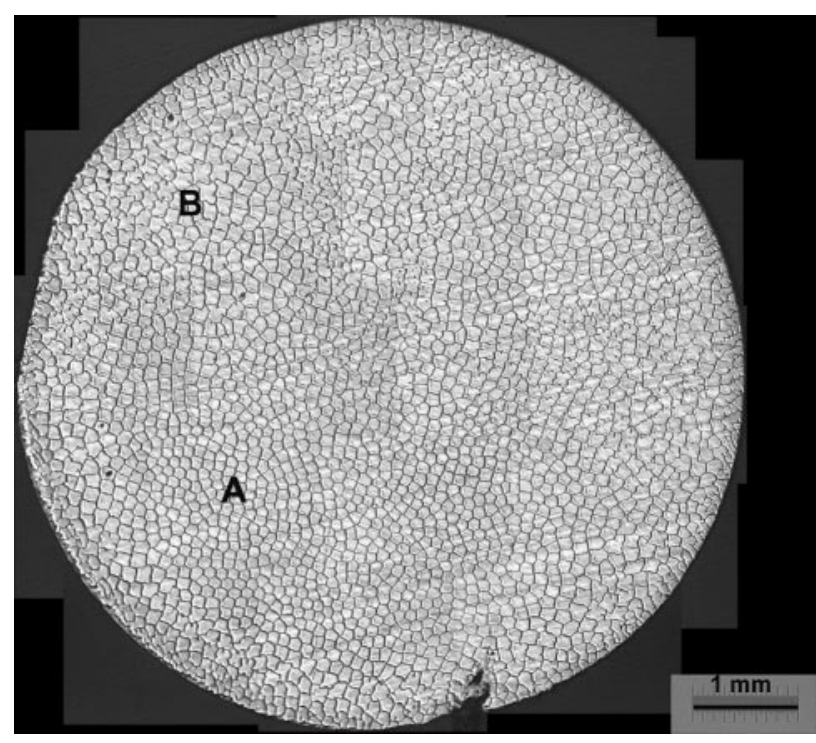

(c)

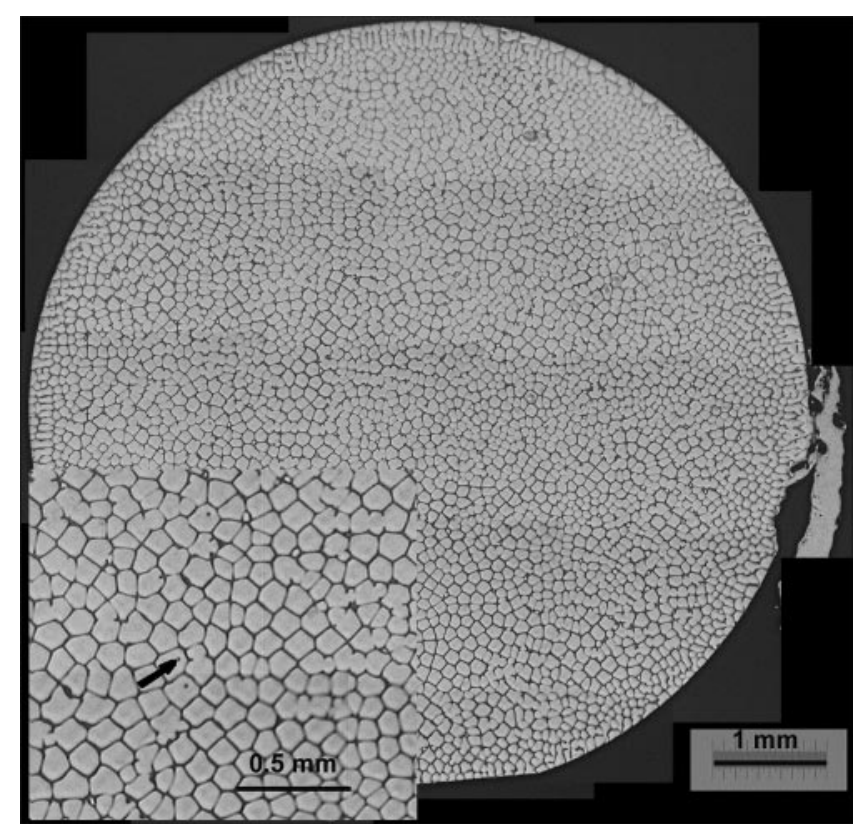

(b)

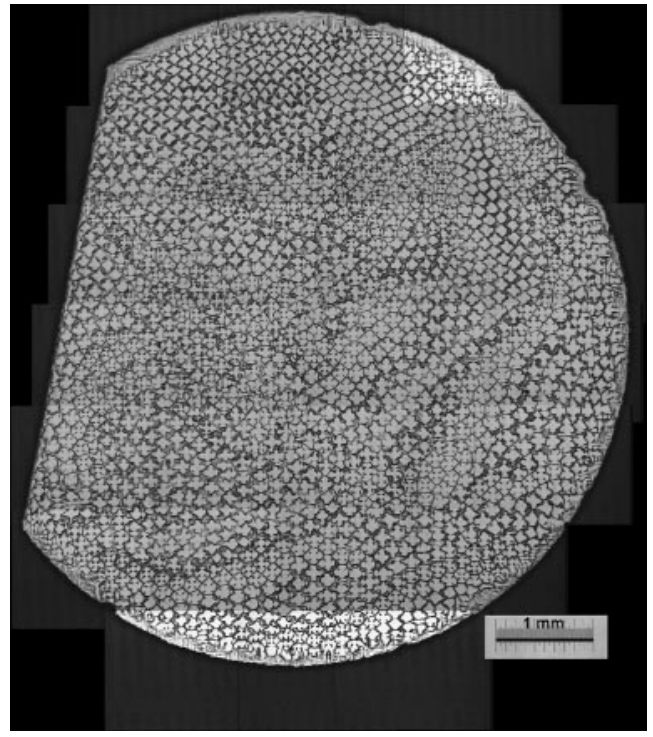

$(d)$

Fig. 2-Transverse microstructures of several Pb-2.2 wt pct Sb alloy single-crystal samples grown along [100] at $164 \mathrm{~K} \mathrm{~cm}^{-1}$. Higher magnification views are presented in the inset. (a) Shallow cells grown at $1.8 \mu \mathrm{m} \mathrm{s}^{-1}$. The inset shows "submerging" cells whose cross sections are much smaller than those of the neighboring cells. (b) Deep cells grown at $2.5 \mu \mathrm{m} \mathrm{s}^{-1}$. Arrow indicates "tip splitting." (c) Cell-to-dendrite transition grown at $5.0 \mu \mathrm{m} \mathrm{s}{ }^{-1}$. Region "A" contains unbranched cells. Region "B" contains branched dendrites. $(d)$ Dendrites grown at $10 \mu \mathrm{m} \mathrm{s}^{-1}$.

Column 12 lists the ratio of these two limits. Columns 13 through 15 list the Gaussian parameters for the first peak observed in the frequency distribution of the nearest and higher-order neighbor spacing. The ratios of the upper (largest $10 \mathrm{pct}$ ) and lower (smallest $10 \mathrm{pct}$ ) limits of the nearest-neighbor spacing are listed in column 16.

\section{Al-4.1 wt pct $\mathrm{Cu}$ alloy}

\section{a. Voronoi Polygons}

Figure 4 shows the center of mass distribution for the two $\mathrm{Al}-\mathrm{Cu}$ samples whose microstructures were presented in Figure 3. Figure 4(a) corresponds to the sample, which was grown for a distance of $3 \mathrm{~cm}$ before being quenched, and
Figure 4(b) corresponds to the one grown for $9 \mathrm{~cm}$ under otherwise identical conditions and then quenched. The distribution of cells is reasonably uniform across the entire sample cross section. The primary spacing values for the two samples, as given by $\sqrt{A / N}$, are almost identical, 125.7 and $124.9 \mu \mathrm{m}$, respectively. This suggests that despite an ongoing local rearrangement of neighboring cells, which continues throughout the directional solidification process, an overall steady state in terms the average primary spacing is established by a solidification distance of only $3 \mathrm{~cm}$. Detailed statistics about these samples is presented in Table I.

The center of mass images were used to obtain the corresponding Voronoi polygons shown in Figure 5. The insets 


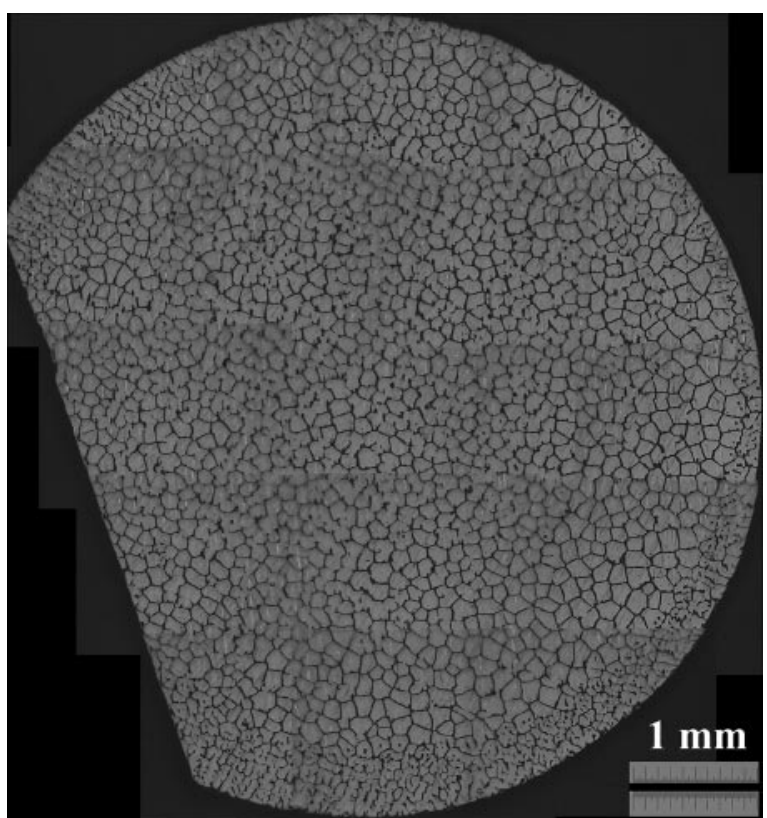

(a)

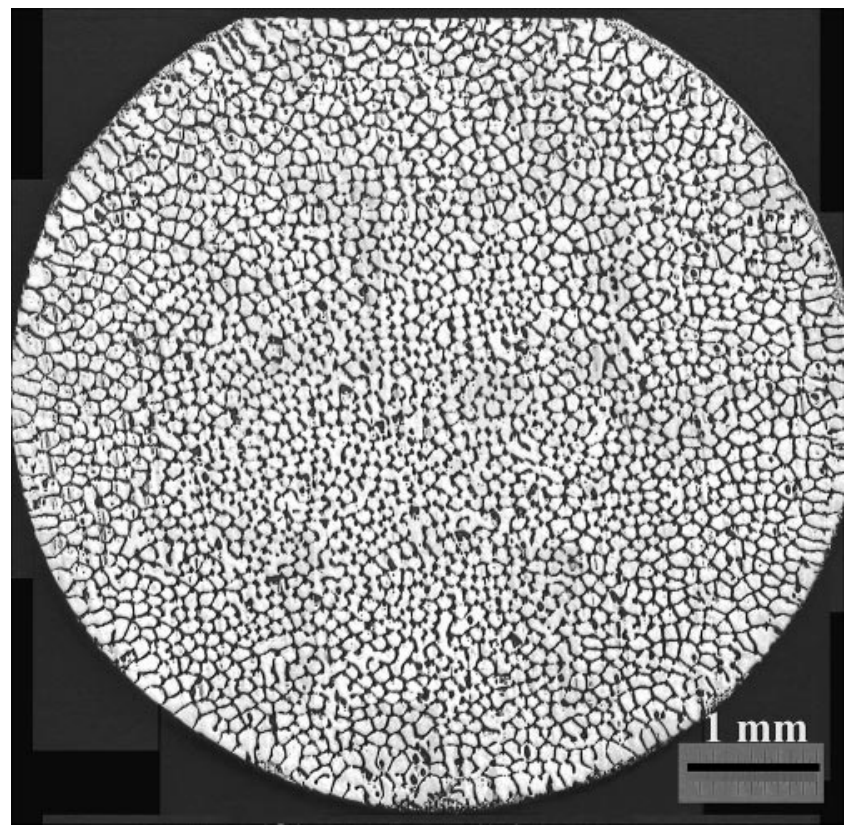

(b)

Fig. 3-Transverse microstructure of Al-4.1 wt pct $\mathrm{Cu}$ alloy single-crystal samples directionally solidified along [100] in the deep cell regime: thermal gradient $110 \mathrm{~K} \mathrm{~cm}^{-1}$ and growth speed $10 \mu \mathrm{m} \mathrm{s}^{-1}$. (a) Directionally solidified for $3 \mathrm{~cm}$ before being quenched. (b) Directionally solidified for $9 \mathrm{~cm}$ before being quenched.

show a typical portion of the sample cross section at higher magnification. The numbers shown within each polygon indicate the corresponding number of its nearest neighbors.

Figure 6 presents the frequency distributions (normalized to a total of $100 \mathrm{pct}$ ) of the number of nearest neighbors for the two samples. Curves in these figures are a Gaussian fit to the data. The corresponding peak parameters for the 3 and $9 \mathrm{~cm}$ translated samples, $A_{0}$, the amplitudes $(46.95 \pm$ 1.08 and $45.83 \pm 1.89), A_{1}$, the center positions $(5.93 \pm$ 0.02 and $5.90 \pm 0.04)$, and $A_{2}$, the widths $(0.87 \pm 0.03$ and
$0.90 \pm 0.05)$, are nearly identical. An overall distribution in the number of neighboring cells is, thus, established after a directional solidification of less than $3 \mathrm{~cm}$. It is evident that the six-sided polygons have the highest frequency. This is in agreement with the earlier observations in $\mathrm{Pb}-\mathrm{Tl}^{[2]}$ and succinonitrile-acetone alloys. ${ }^{[4]}$

\section{b. Minimum spanning tree}

Figure 7(a) shows the MSTs for the two Al-Cu samples being examined. The two samples appear to have nearly identical MSTs. The frequency distribution of the branch lengths for these two samples is shown in Figure 7(b). The frequency distribution is Gaussian, as indicated by the high values of the parameter, $R^{2}, 0.985$ and 0.987 , respectively, for the 3 and $9 \mathrm{~cm}$ grown samples. The mean branch lengths for the 3 and $9 \mathrm{~cm}$ grown samples are $109.3 \pm 15.5$ and $109.0 \pm 13.2 \mu \mathrm{m}$, respectively (Table I column 10).

Hunt and $\mathrm{Lu}^{[14]}$ have suggested that the ratio of the maximum and the minimum spacing for the cellular morphologies is two. Since an accurate determination of the minimum and maximum spacing involves considerable uncertainty, we have used the Gaussian peak to determine the upper (corresponding to the largest 10 pct of the spacing population) and lower (corresponding to the smallest 10 pct of the spacings) limits of the spacings. The ratio of these limits is observed to be 1.44 and 1.35 in the two $\mathrm{Al}-\mathrm{Cu}$ alloy samples examined here (Table I).

The $m$ and $\sigma$ values obtained from the MST analyses are plotted in Figure 8. This figure also contains data from the $\mathrm{Pb}-2.2$ wt pct samples, which will be discussed in Section 1-2. The solid line in this figure is for a simulated hexagonal tessellation of points with increasing amount of superimposed random noise generated by a uniformly distributed, random-number generator. The extent of noise, defined as the ratio of the maximum amount of random displacement a grid point could have and the normal distance between two grid points, has been varied at $10 \mathrm{pct}$ increments. Increasing the amount of noise increases $\sigma$ and decreases $m$. The same behavior was observed by superimposing a random noise that had a Gaussian distribution. For example, a hexagonal tessellation that is based on 25 $\mu \mathrm{m}$ nearest-neighbor spacing and contains superimposed, uniformly distributed, random noise varying within $\pm 6 \mu \mathrm{m}$ gives $m=0.89$ and $\sigma=0.12$. The same tessellation when superimposed with a random Gaussian noise having a mean of zero and standard deviation of $32 \mu \mathrm{m}$ yields $m=0.90$ and $\sigma=0.12$. The $m$ and $\sigma$ values from the two $\mathrm{Al}-\mathrm{Cu}$ samples (0.87 and 0.11$)$ are nearly identical and are close to the hexagonal tessellation containing about 50 pct of superimposed noise. Based on similar observations in $\mathrm{Pb}-$ $\mathrm{Tl}$ alloy, ${ }^{[2]}$ it has been suggested that the distribution of cells can be described as a hexagonal tessellation with superimposed Gaussian noise. However, as indicated subsequently the power spectrums obtained by taking the FFTs of the images made up of the cell centers do not support this view.

\section{c. Fast fourier transform}

Figure 9 shows the power spectrum images obtained by taking FFTs of the cell center images contained in Figure 4. Let us recall that in these FFT images the intensity (power spectrum magnitude) corresponding to the highest frequency appears closest to the center. For the Al-Cu deep cells being examined here, the FFT shows one diffused 


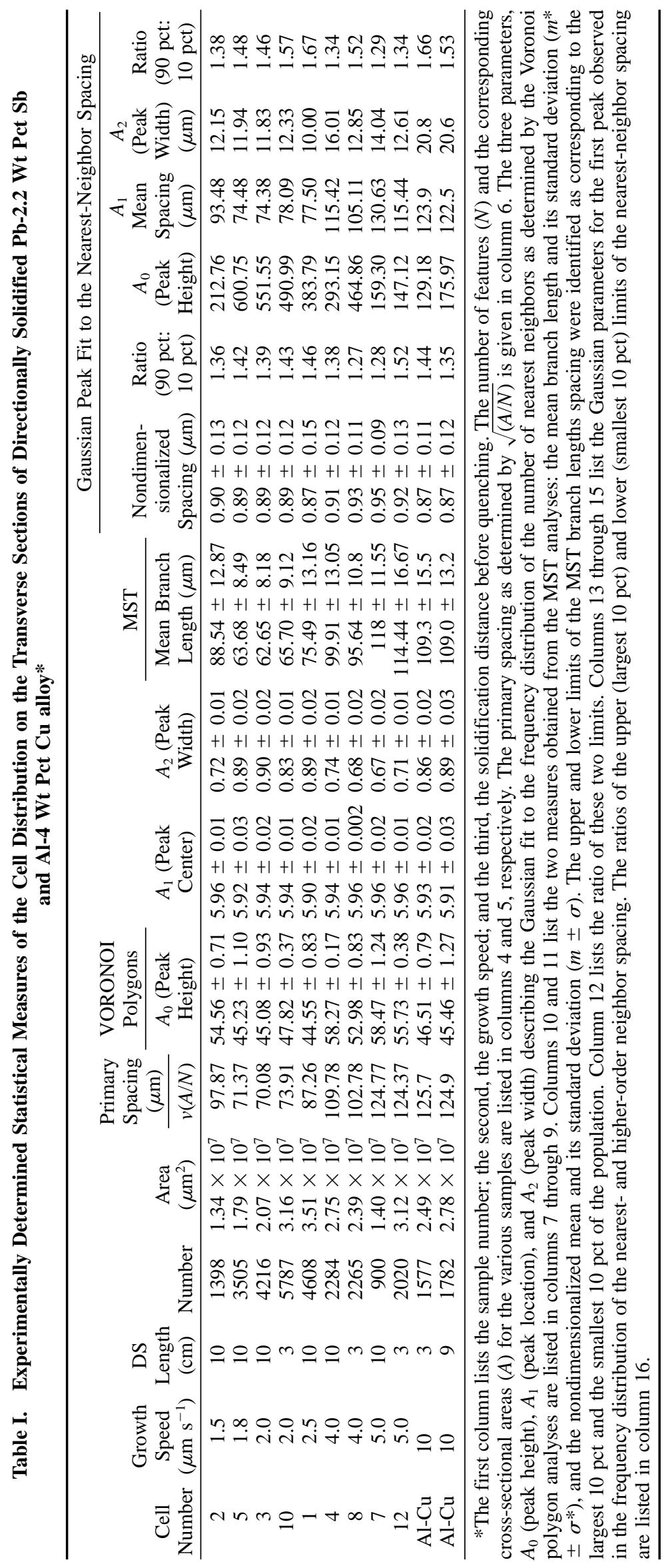




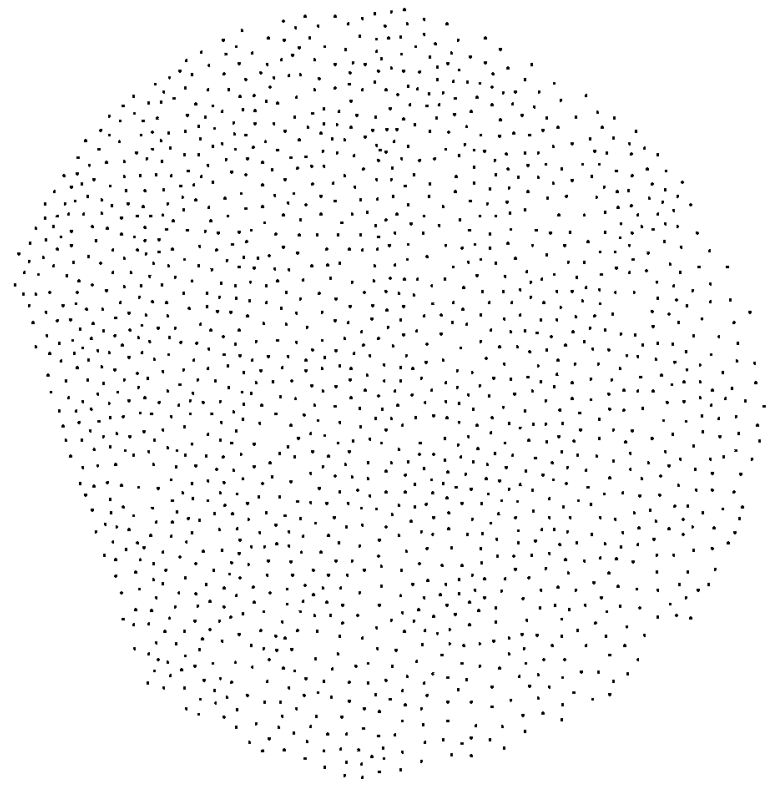

(a)

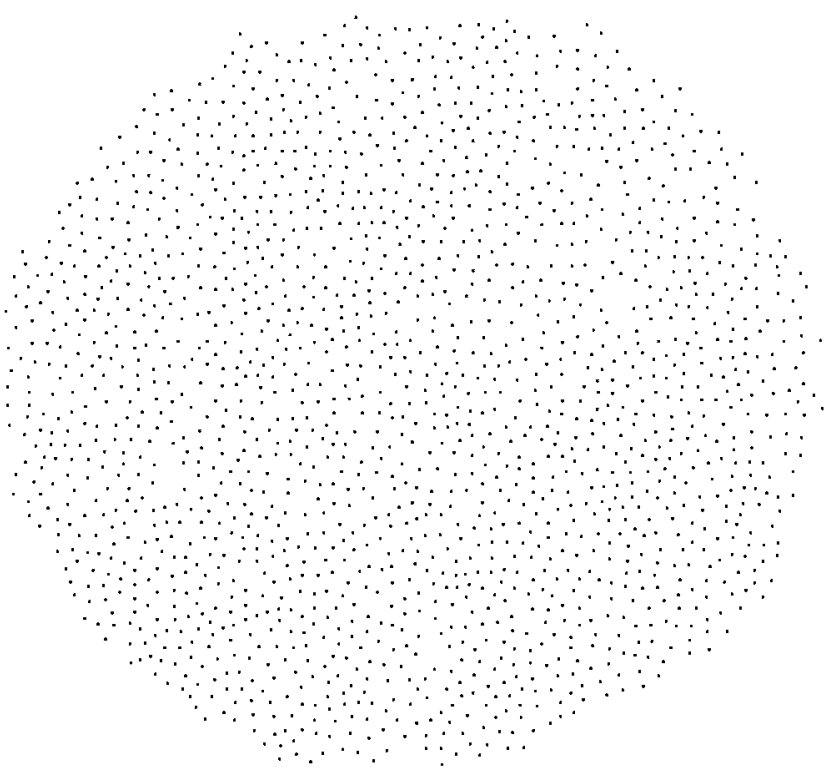

(b)

Fig. 4-Cell centers for the two Al-Cu alloy transverse microstructures shown in Fig. 3. (a) Directionally solidified for 3 cm before being quenched. (b) Directionally solidified for $9 \mathrm{~cm}$ before being quenched.

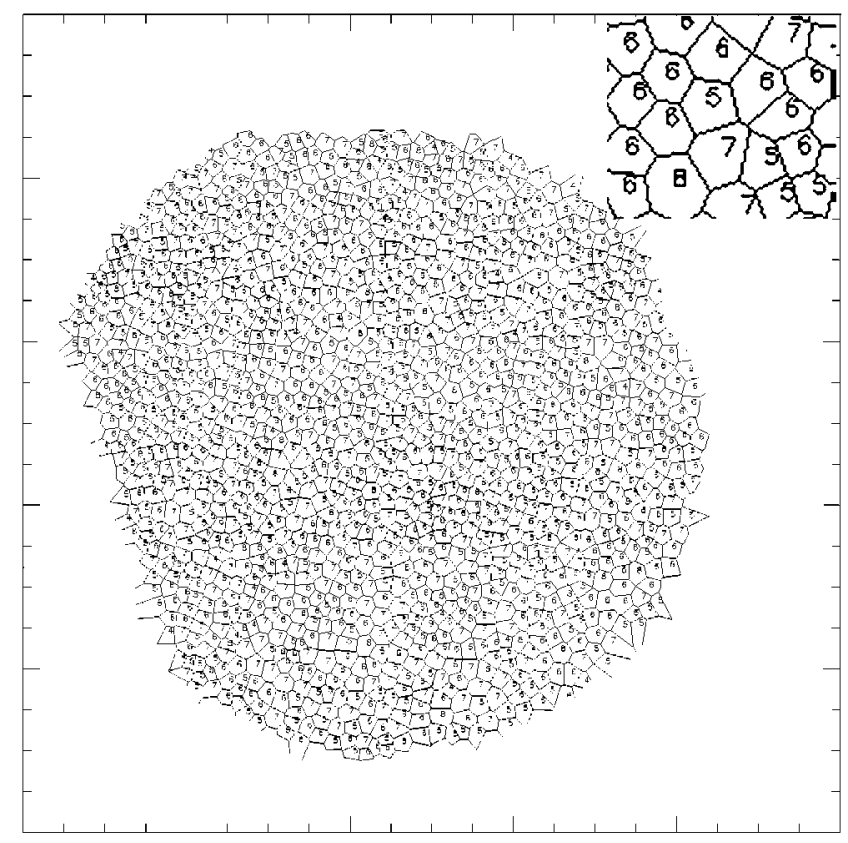

(a)

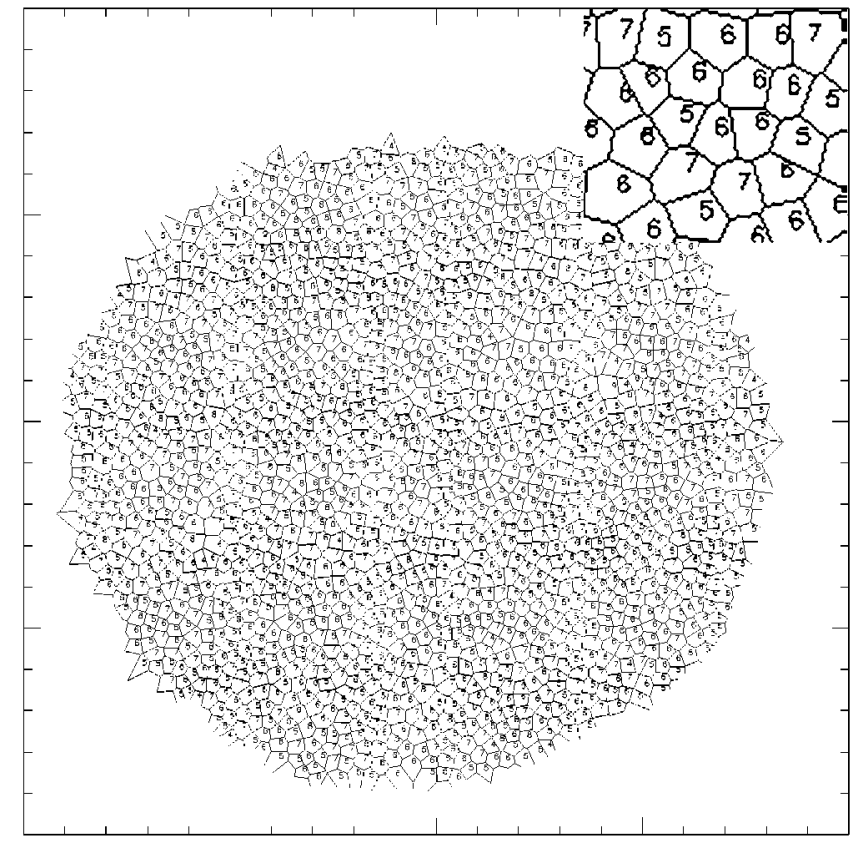

(b)

Fig. 5-Voronoi polygons corresponding to the two Al-4.1 wt pet Cu cellular microstructures shown in Figure 3 . (a) Directionally solidified for 3 cm before being quenched. (b) Directionally solidified for $9 \mathrm{~cm}$ before being quenched.

broad-ring pattern, suggesting that a well-defined spacing with some superimposed noise exists only for the nearest neighbors. There are no rings corresponding to the second or third nearest neighbors. The ring pattern for the cells also suggests that there is no preferred orientation along which the cells may be aligned.' A similar ring pattern is observed for all the samples examined in this study.

Let us now compare the experimentally observed FFT image (Figure 9(b)) with the FFT images obtained from the lattices simulated by hexagonal tessellation and superimposed random noise (Figure 10). Figure 10(a) shows a hexagonal tessellation with 50 pct superimposed, uniformly distributed, random noise, and Figure 10(b) shows the corresponding power spectrum image. The power spectrum consists of six spots arranged as hexagons and additional weaker intensity spots surrounding these. The inherent hexagonal symmetry of the lattice is displayed by the power spectrums even after superimposing 70 to 80 pct uniformly 


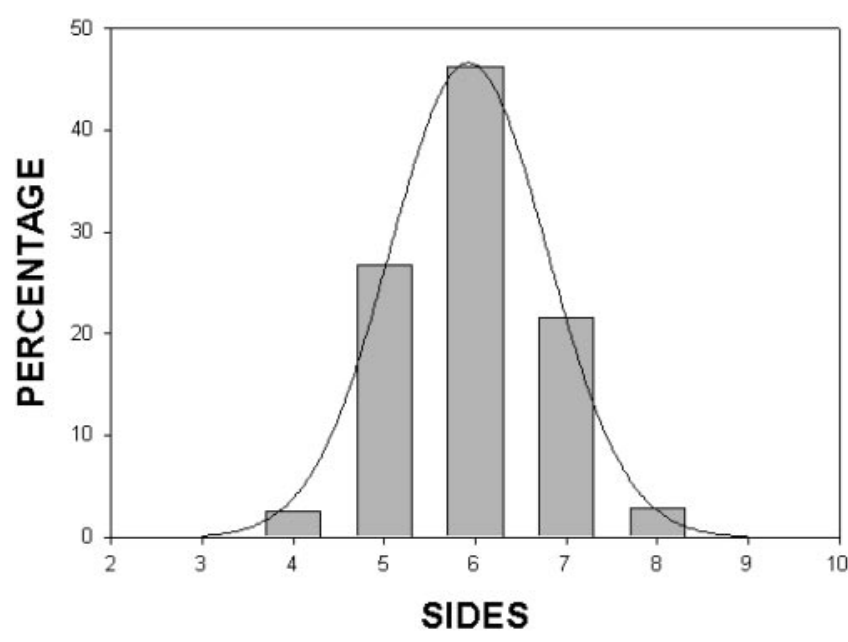

(a)

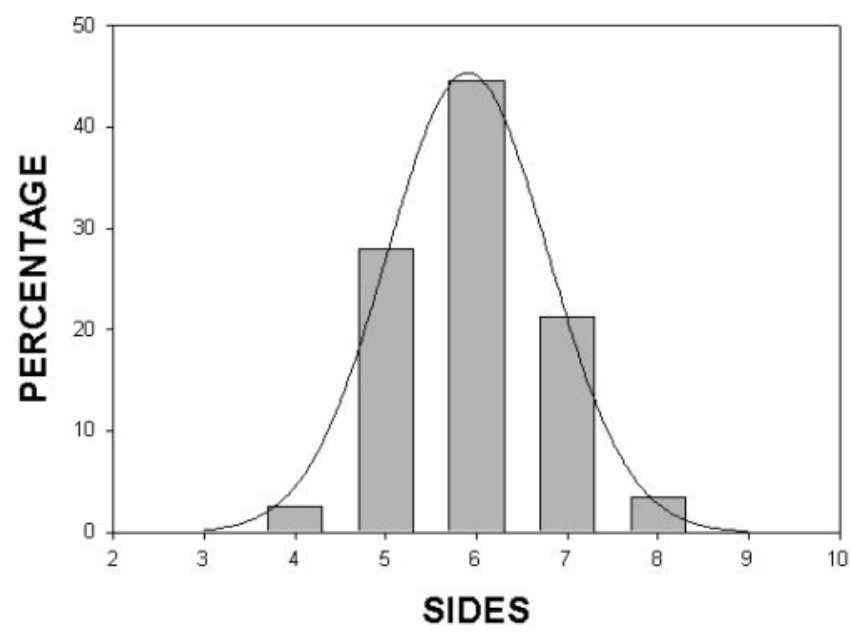

(b)

Fig. 6-Frequency distribution of the number of nearest neighbors in directionally solidified Al-Cu alloy deep cells. (a) Directionally solidified for $3 \mathrm{~cm}$ before being quenched. (b) Directionally solidified for $9 \mathrm{~cm}$ before being quenched.

distributed, random noise. The hexagonal tessellations, having superimposed Gaussian noise (Figure 10(c)), also show a similar FFT power-spectrum image (Figure 10(d)). These FFT power-spectrum images are different from the diffused one-ring pattern that is experimentally observed for cellular morphologies (Figure 9). This observation suggests that in order to simulate the cellular distribution some rotational noise should also be added to the hexagonal tessellations in addition to the previously described random noise.

\section{d. Primary spacing distribution}

Figure 11(a) compares the frequency distribution of the nearest and higher-order spacing for the two $\mathrm{Al}-\mathrm{Cu}$ alloy samples grown for 3 and $9 \mathrm{~cm}$, respectively, before being quenched. The two distributions are almost identical. Figure 11(b) shows the Gaussian amplitude fit to the nearest-neighbor spacing data after subtracting the linear background. The mean nearest-neighbor spacings for the 3- and 9-cm translated samples obtained in this manner are nearly the same, $123.9 \pm 20.8$ and $122.5 \pm 20.6 \mu \mathrm{m}$ (Table I), respectively, confirming the previous observations about reaching an overall steady-state distribution of cells by a solidification distance of about $3 \mathrm{~cm}$. The ratios of the upper and lower limits, as defined earlier for the MST branch-length distribution, were also obtained for the frequency distribution of the nearest-neighbor spacing. The ratio is 1.66 (for directional solidification (DS) length of $3 \mathrm{~cm}$ ) and 1.53 (for DS length of $9 \mathrm{~cm}$ ) in the two $\mathrm{Al}-\mathrm{Cu}$ alloy samples examined here (Table I).

\section{e. Radial distribution factor}

Figure 12 compares the radial distribution factors for the two Al-Cu alloy samples grown for 3 and $9 \mathrm{~cm}$, respectively. There is only one distinct peak corresponding to the nearest neighbors. It suggests that the ordering is limited only to the nearest neighbors. The scatter in the second and higherorder neighbor spacing is too large to yield any distinct peak. The extent of ordering, as given by the height of the first peak, is similar in the two samples, indicating that an overall steady state is reached after solidifying for about $3 \mathrm{~cm}$.

\section{2. $P b-2.2$ wt pct $S b$ alloy}

Let us now examine the cellular distributions in the two sets of the $\mathrm{Pb}-2.2 \mathrm{wt}$ pct $\mathrm{Sb}$ samples grown with different morphologies at a thermal gradient of $164 \mathrm{~K} \mathrm{~cm}^{-1}$. Similar to the Al-Cu alloy samples just described, one set of $\mathrm{Pb}-\mathrm{Sb}$ samples was solidified for a distance of $3 \mathrm{~cm}$ before being quenched, and the other was solidified for $10 \mathrm{~cm}$ before being quenched. Three different growth morphologies have been studied: the shallow cell $\left(2 \mu \mathrm{m} \mathrm{s}^{-1}\right)$, the deep cell (4 $\left.\mu \mathrm{m} \mathrm{s}^{-1}\right)$, and the cell-dendrite transition $\left(5 \mu \mathrm{m} \mathrm{s}^{-1}\right)$. All the $\mathrm{Pb}-\mathrm{Sb}$ samples were grown in the [100] crystal orientation from the same pure lead, single-crystal seed.

Figure 13(a) plots the mean primary spacing, as measured by the Gaussian peak-fit analysis of the nearest-neighbor frequency distribution, as a function of growth speed. The three peak-fit parameters $\left(A_{0}, A_{1}\right.$, and $\left.A_{2}\right)$ for all the $\mathrm{Pb}-\mathrm{Sb}$ samples are listed in Table I. Figure 13(a) shows the previously described, primary-spacing trend of an initial decrease in the shallow cell regime followed by an increase in the deep cell regime and the sharp rise near the cell-todendrite transition. Further increase in growth speed results in decreased primary-dendrite spacing. The data are better visualized (Figure 13(b)) when plotted as a function of the effective gradient of constitutional supercooling, $S^{*}=(1-$ $\left.D_{1} G k / V m_{1} C_{0}(k-1)\right)$, where $D_{1}$ is the diffusivity of antimony in lead; $3 \times 10^{-5} \mathrm{~cm}^{2} \mathrm{~s}^{-1 ;[15]} G$ is the effective thermal gradient at the liquid-solid interface, $112 \mathrm{~K} \mathrm{~cm}^{-1} ; k$ the solutal partition coefficient $(0.4) ;{ }^{[16]} V$ is the growth speed; $m_{1}$ is the liquidus slope (6.8 wt pct Sb K $\left.{ }^{-1}\right) ;{ }^{[16]}$ and $C_{0}$ the solute content of the melt, 2.2 wt pct $\mathrm{Sb}$. The filled symbols correspond to those experiments where the samples were quenched after a solidification distance of $10 \mathrm{~cm}$, and the open symbols are for the $3 \mathrm{~cm}$. The arrow indicates the cellto-dendrite transition. It is apparent that for all the growth conditions examined in this study the mean primary spacing after $3 \mathrm{~cm}$ of DS is nearly the same as that after $10-\mathrm{cm}$ DS. This behavior is also confirmed by comparing the primary spacing values obtained by using the $\sqrt{A / N}$ relationship (given in column 6 in Table I). The spacing values for the 3- and 10-cm translation distances respectively are: 73.9 and $70.1 \mu \mathrm{m}$ for the $2 \mu \mathrm{m} \mathrm{s}^{-1}, 102.8$ and $109.8 \mu \mathrm{m}$ for the 4 $\mu \mathrm{m} \mathrm{s}^{-1}$, and 124.4 and $124.8 \mu \mathrm{m}$ for the $10 \mu \mathrm{m} \mathrm{s}^{-1}$ growth speeds. Apparently a translation distance of $3 \mathrm{~cm}$ is sufficient to ensure a steady state in terms of the overall mean spacing.

Lead-antimony alloy samples also show the ratio of the 

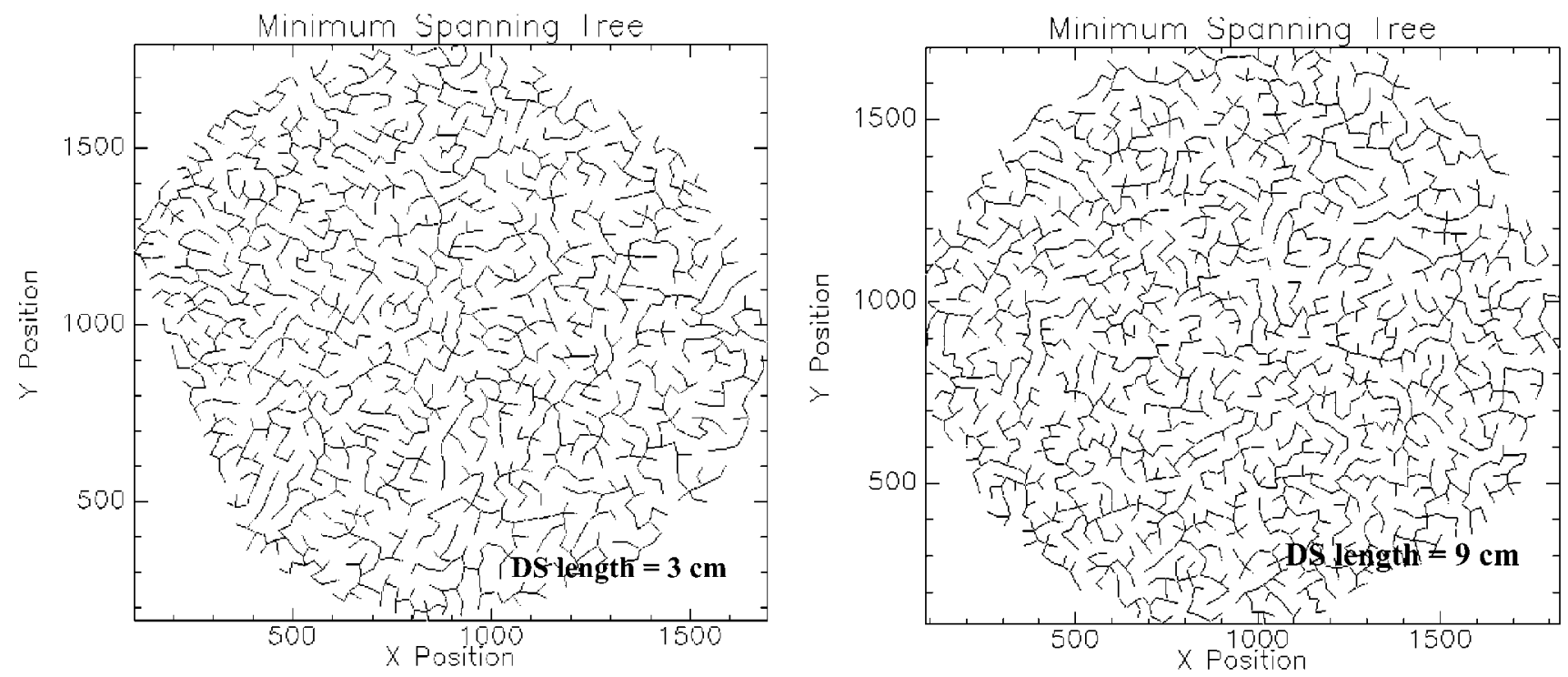

(a)
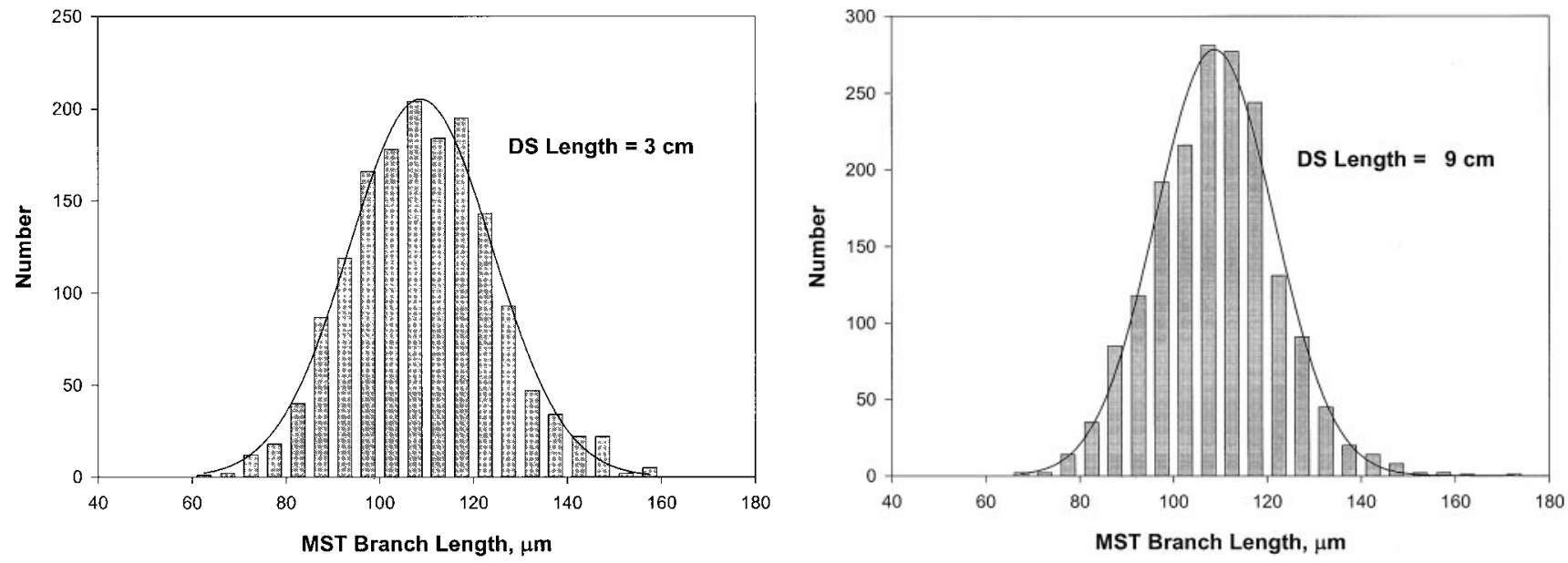

(b)

Fig. 7-MST obtained from the cell center images shown in Fig. 4 for two Al-4.1 wt pct Cu alloy samples directionally solidified for 3 cm and for 9 cm before being quenched. (a) MST images: DS length $=3 \mathrm{~cm}$ and DS length $=9 \mathrm{~cm} .(b)$ MST branch length histograms for DS length $=3 \mathrm{~cm}$ and DS length $=9 \mathrm{~cm}$.

upper and lower limits in the primary spacing to be about 1.5, as was observed for the Al-Cu samples examined earlier. An overall average value for this ratio, between the highest 10 pct and the lowest 10 pct of the primary spacings (Table I), is observed to be $1.43 \pm 0.11$.

\section{a. Voronoi polygons}

Figure 14 compares the frequency distribution of the number of nearest neighbors obtained from the Voronoi polygon analyses of the three sets of samples grown at $2 \mu \mathrm{m} \mathrm{s}$ (shallow cells), $4 \mu \mathrm{m} \mathrm{s}^{-1}$ (deep cell), and $5 \mu \mathrm{m} \mathrm{s}^{-1}$ (cell to dendrite). They all show the dominance of six nearest neighbors. There is very little scatter in the $A_{1}$ values for the $\mathrm{Pb}-\mathrm{Sb}$ alloys listed in Table I, the mean corresponds to $5.94 \pm 0.02$. The frequency distributions of the number of nearest neighbors are almost identical for the 3 and $10 \mathrm{~cm}$ of directional solidification.

The ratio of the peak height to peak width, $A_{0} / A_{1}$, is a measure of the scatter in the distribution. If we ignore the data for the lowest growth-speed sample $\left(1.5 \mu \mathrm{m} \mathrm{s}^{-1}\right)$ where the nearest-neighbor distribution on the transverse section was significantly affected by the solid-state coarsening described earlier (Figure 1(b)), the shallow cells appear to have more scatter (mean $A_{0} / A_{1}=52$ ), as compared with the deep cells $\left(A_{0} / A_{1}=78\right)$ or the cell-to-dendrite transition $\left(A_{0} / A_{1}=83\right)$. The $\mathrm{Al}-\mathrm{Cu}$ deep cell samples also yield $A_{0} / A_{1}=52$.

\section{b. Minimum spanning tree}

The $m-\sigma$ values for the $\mathrm{Pb}-\mathrm{Sb}$ alloys from Table I have been plotted in Figure 8. The filled symbols are for the 10$\mathrm{cm}$ translation distance, and the open symbols are for the $3-\mathrm{cm}$ DS. The corresponding growth speeds are indicated in the figure. As previously noted, the solid line corresponds to a hexagonal tessellation with increasing amount of superimposed uniformly distributed random noise. As indicated in this figure, the noise has been incremented at a 10 pct interval. The value of $m$ decreases and that of $\sigma$ increases with increasing amount of superimposed random noise. There does not appear to be any significant difference 


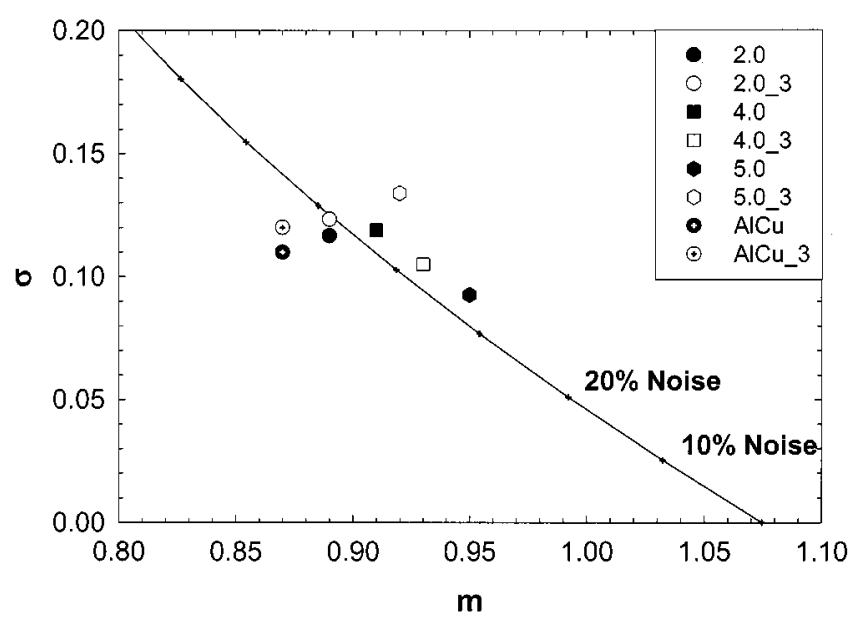

Fig. 8- The $m-\sigma$ plot for the directionally solidified $\mathrm{Pb}-2.2$ wt pct $\mathrm{Sb}$ and Al-4.1 wt pet. Cu alloy single-crystal samples. Filled symbols correspond to the samples that were directionally solidified for a distance of 9 or 10 $\mathrm{cm}$ before being quenched, and the open symbols for samples grown for $3 \mathrm{~cm}$ before being quenched. The solid line corresponds to a hexagonal tessellation with increasing amount of superimposed random noise generated by a uniformly distributed-random-number generator. Noise has been incremented at $10 \mathrm{pct}$ interval.

between the 3- and 10- $\mathrm{cm}$ translation distances for the cell or cell-to-dendrite samples (growth speed from 1.5 to $4 \mu \mathrm{m}$ $\mathrm{s}^{-1}$ ). However, for the dendrite sample grown at $5 \mu \mathrm{m} \mathrm{s}^{-1}$, there is less noise in the sample after a growth of $10 \mathrm{~cm}$, as compared with that of $3 \mathrm{~cm}$. The experimentally observed $m$ and $\sigma$ values are $0.895 \pm 0.035$ and $0.117 \pm 0.017$, respectively. These values are nearly identical to 0.91 for $m$ and 0.12 for $\sigma$ reported for the $\mathrm{Pb}-\mathrm{Tl}$ alloy cells. ${ }^{[2]}$

An examination of Table I shows that the ratio of the upper and lower limits of the MST branch lengths is 1.38 \pm 0.08 . This is similar to the value of $1.43 \pm 0.11$ obtained from examining the nearest-neighbor distribution.

The FFT images of all the cellular $\mathrm{Pb}-\mathrm{Sb}$ samples were identical to those for the Al-Cu samples described in Figure 9. They all consisted of one diffused-ring pattern.

\section{Radial distribution factor}

Figure 15 compares the radial distribution factor in the $\mathrm{Pb}-\mathrm{Sb}$ alloy samples that were solidified for a translation distance of 3 and $10 \mathrm{~cm}$ before being quenched. The shallow cell sample grown at $2 \mu \mathrm{m} \mathrm{s}^{-1}$ (Figure 15(a)) has only one peak corresponding to the nearest-neighbor ordering. However, the deep cell sample grown at $4 \mu \mathrm{m} \mathrm{s}^{-1}$ (Figure $15(\mathrm{~b}))$ and the cell-to-dendrite sample grown at $5 \mu \mathrm{m} \mathrm{s}^{-1}$ (Figure 15(c)) show a distinct second peak, indicating some second nearest-neighbor ordering. The amplitude of the nearest-neighbor peak for the shallow cells is significantly less than that for the deep cell or cell-to-dendrite samples. This suggests that the shallow cell morphology is more disordered, as compared with the deep cells. For the shallow cells (Figure 15(a)) and the deep cells (Figure 15(b)), the radial distribution factors are nearly identical for the 3 and 10 $\mathrm{cm}$ of directional solidification. However, for the cell-todendrite sample grown at $5 \mu \mathrm{m} \mathrm{s}^{-1}$, the amplitude of the first and the second nearest-neighbor peak is higher in the 10-cm DS sample, as compared with the 3-cm DS sample. It appears that for this growth condition the microstructure undergoes continued ordering throughout the directional

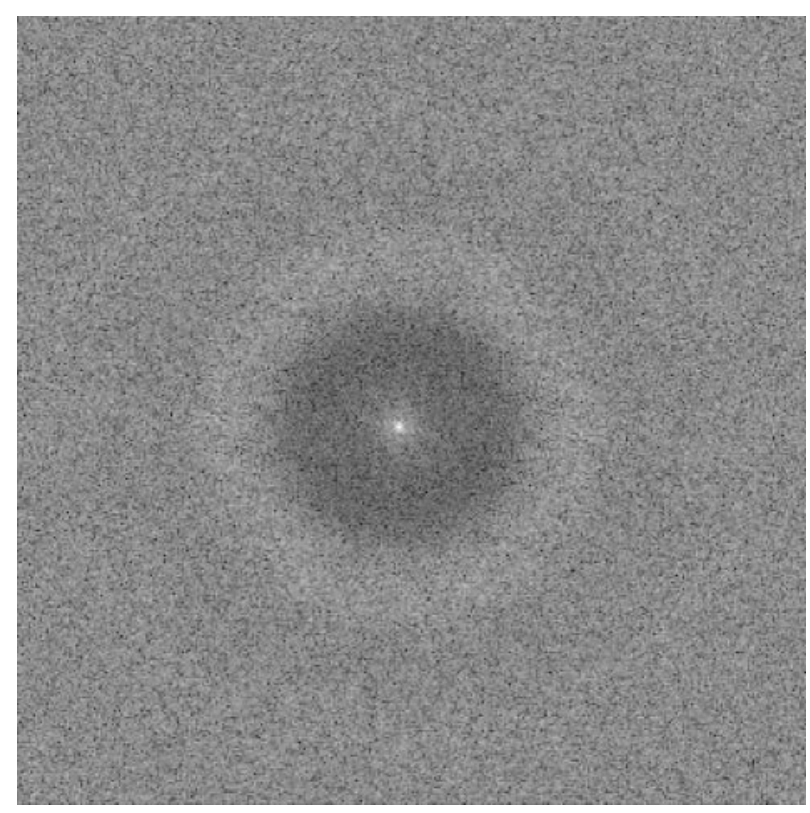

(a)

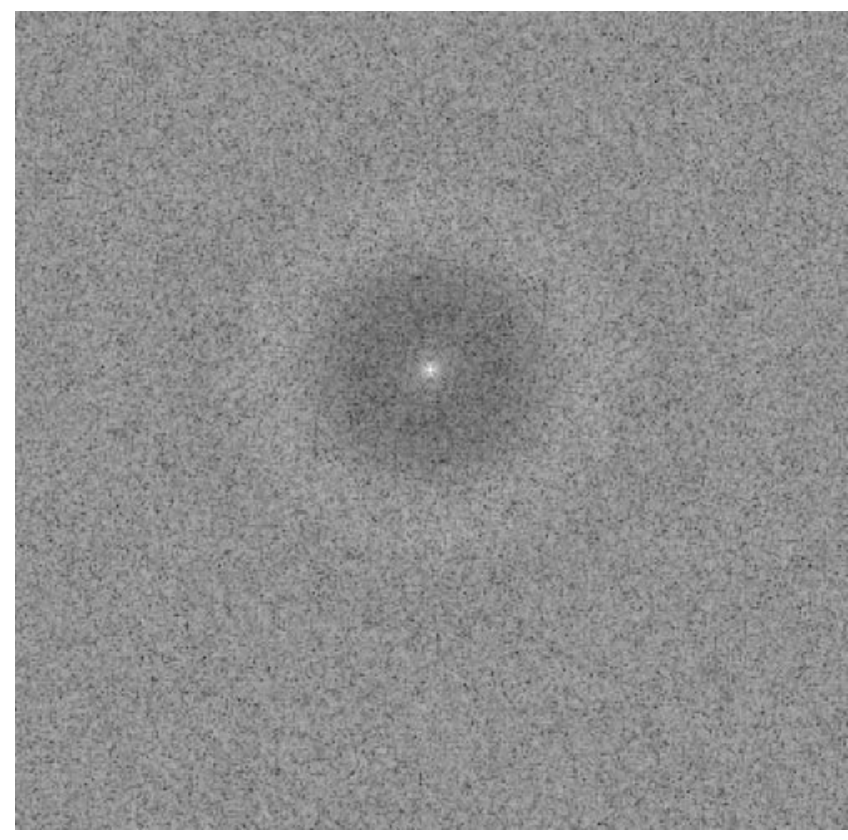

(b)

Fig. 9-Power spectrum images obtained by taking the fast Fourier transforms of the cell center images shown in Fig. 4. The single diffused ring pattern is similar to the X-ray diffraction pattern from liquids. (a) Directionally solidified for $3 \mathrm{~cm}$ before being quenched. (b) Directionally solidified for $9 \mathrm{~cm}$ before being quenched.

solidification process. It is likely that the presence of side branches and their crystallographic nature, side branches grow only along $\langle 100\rangle$ directions, is responsible for this continued ordering of the primary dendrites during directional solidification.

\section{DISCUSSION}

Based on the predominance of six nearest neighbors (Figures 6 and 14) and the agreement of the MST characteristics 


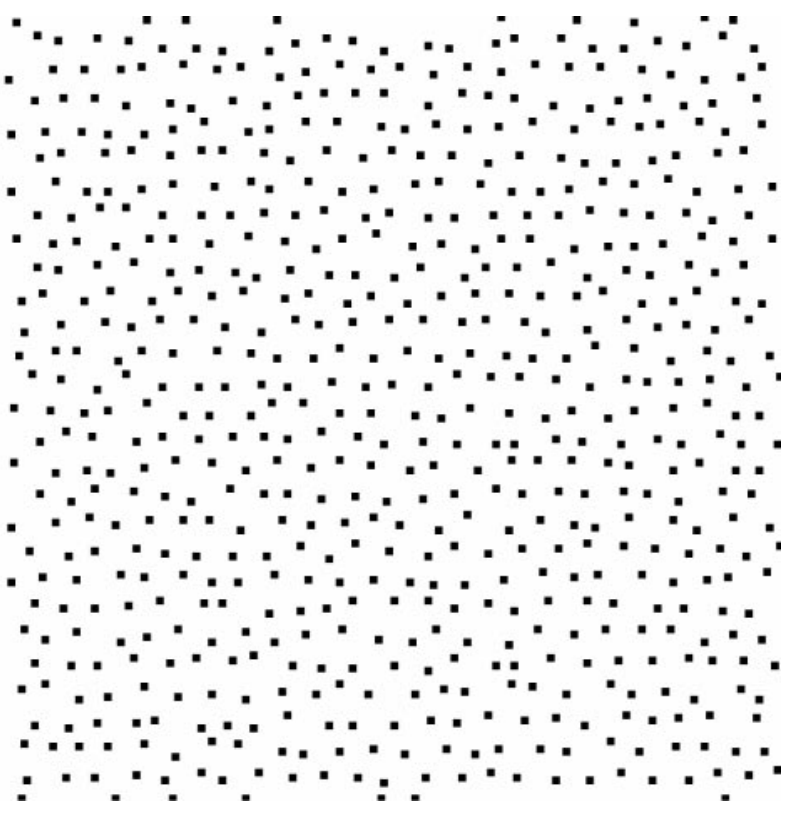

(a)

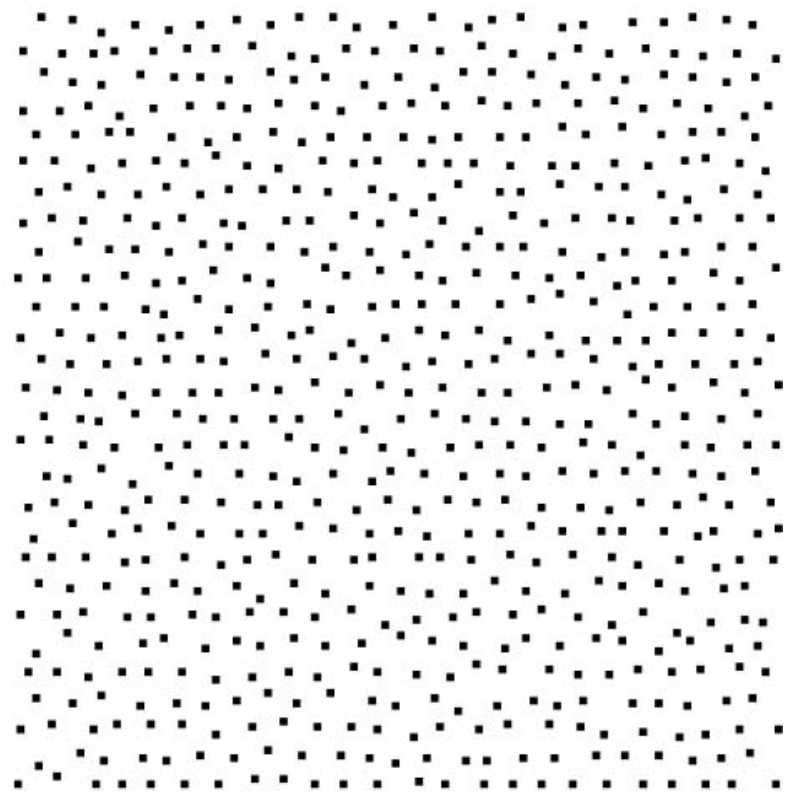

(c)

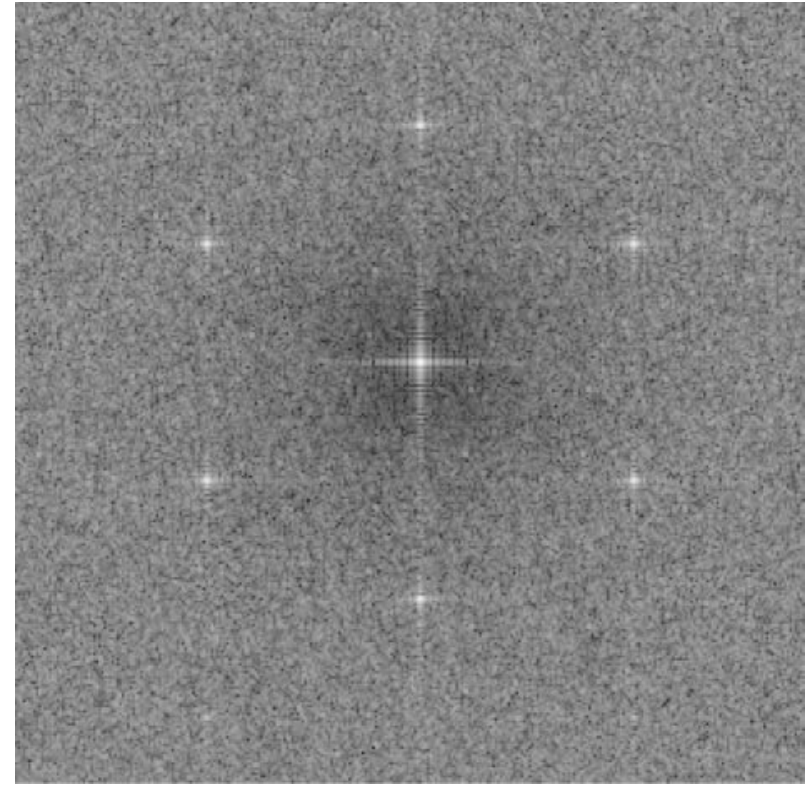

(b)

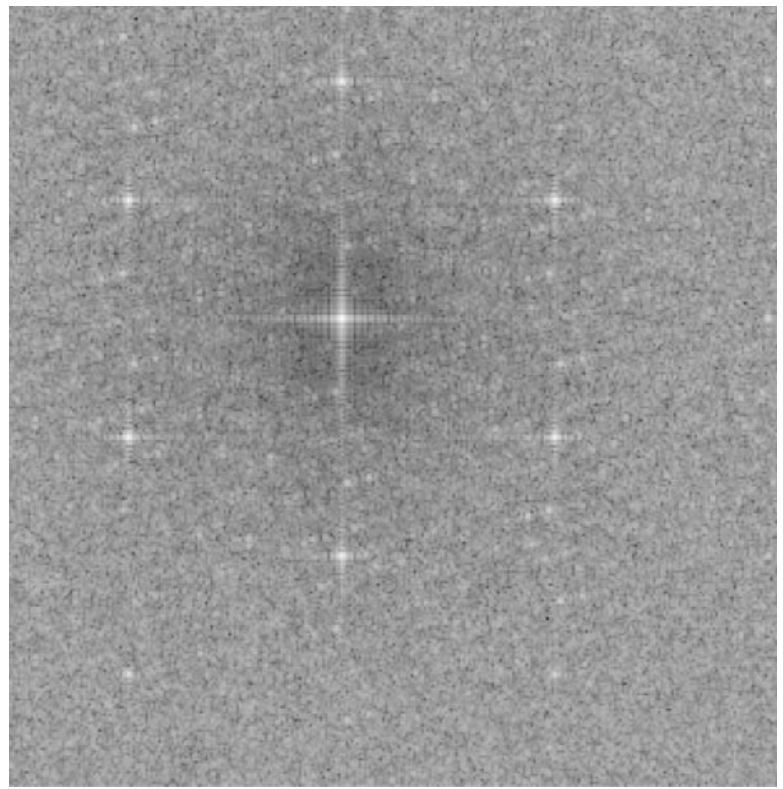

$(d)$

Fig. 10-Hexagonal tessellations with superimposed random noise and the power spectrum image obtained by taking their FFT. (a) Hexagonal tessellation with $25-\mu \mathrm{m}$ nearest-neighbor spacing and superimposed uniformly distributed random noise varying within $\pm 6 \mu \mathrm{m}$. (b) Power spectrum image from FFT of (a). (c) Hexagonal tessellation with 25- $\mu$ m nearest-neighbor spacing and superimposed Gaussian random noise with mean of zero and standard deviation of $32 \mu \mathrm{m} .(d)$ Power spectrum image from FFT of Fig. 10(c).

$(m, \sigma)$ with the simulated hexagonal tessellation having about 50 pct superimposed, uniformly distributed, random noise (Figure 8), it appears that the cells have similar hexagonal arrangement, as has been suggested in the literature. ${ }^{[2]}$ However, a comparison of the FFT power spectrums of the cell centers (consisting of one diffused ring, Figure 9), with those obtained from the lattices based on the hexagonal tessellations having superimposed random noise (showing distinct nearest-neighbor spots, Figures 10 (b) and (d)), does not support this view. The diffused one-ring pattern is similar to the well-known X-ray diffraction patterns obtained from liquids. The liquidlike distribution of cells is also supported by the similarity between their radial distribution factor (Figures 12 and 15) and the radial distribution factor for the liquids.

A translation distance of about $3 \mathrm{~cm}$ is sufficient to ensure that an overall steady state is achieved in terms of the mean primary spacing becoming constant for both the Al-4.1 wt pct $\mathrm{Cu}$ and $\mathrm{Pb}-2.2$ wt pct $\mathrm{Sb}$ alloys. This is supported by all three measures of the mean primary spacing examined in this study: (cross-section/number of cells) ${ }^{1 / 2}$, mean branch length from the MST, and the location of the nearest-neighbor peak in a frequency distribution of the nearest and higher-order spacing. However, localized interaction 


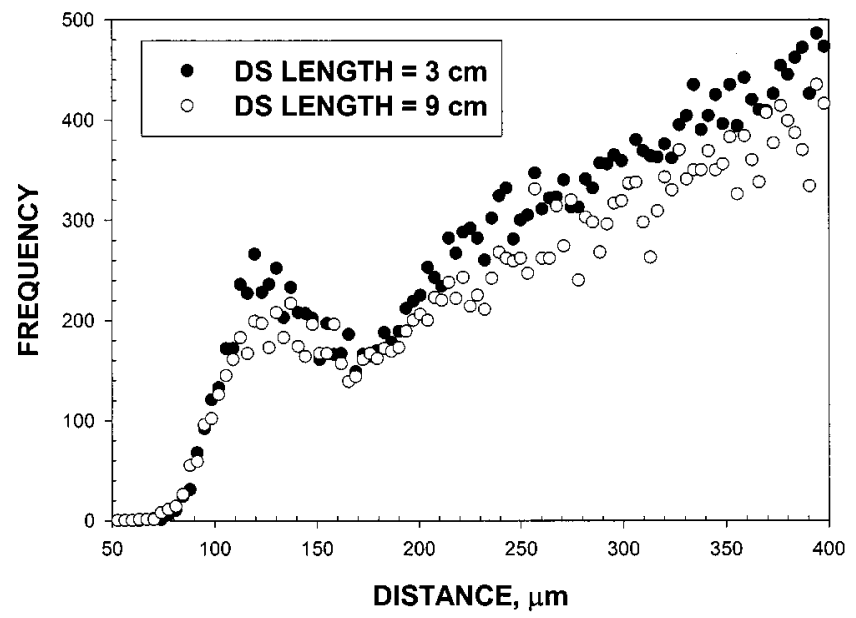

(a)

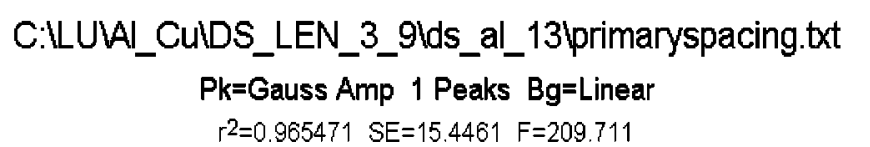

\section{C:LUAI_CuYDS_LEN_3_9lds_al_12 Yprimaryspacing.txt} $r^{2}=0.965471$ SE $=15.4461 \quad F=209.711$
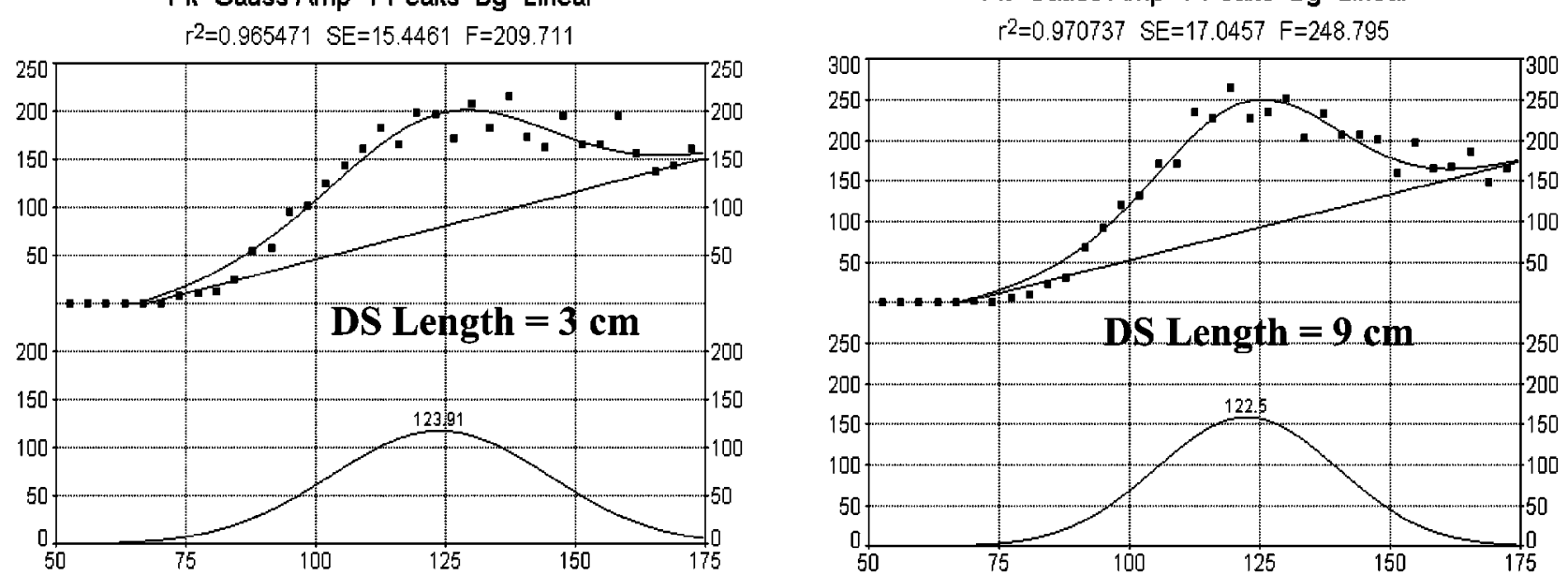

(b)

Fig. 11-An overall steady-state mean primary spacing is obtained for the deep cell samples of Al-Cu alloy by directional solidification of $3 \mathrm{~cm}$. (a) Frequency distribution of the nearest and higher-order spacings. Filled symbols correspond to a solidification distance of $9 \mathrm{~cm}$ before being quenched. The open symbols are for a growth of $3 \mathrm{~cm}$ before being quenched. (b) Gauss amplitude analysis of the nearest-neighbor peaks in (a) to obtain primary arm spacing values.

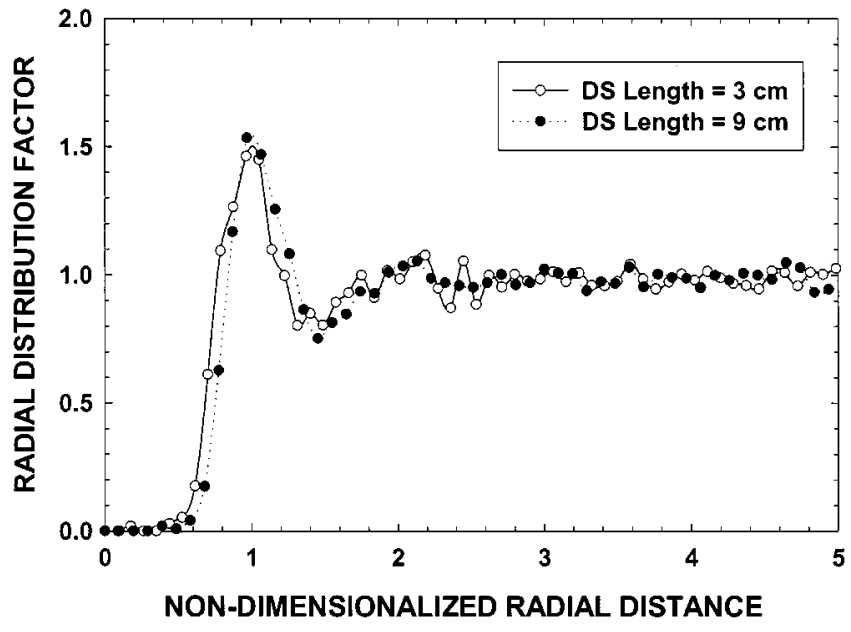

Fig. 12-A comparison of the radial distribution factor in the two $\mathrm{Al}-\mathrm{Cu}$ alloy samples grown for 9 and $3 \mathrm{~cm}$, respectively, before being quenched. among the immediate neighbors continues throughout the process of directional solidification. For the shallow cells, this interaction is manifested by the continuing process of cell submerging. About 14 pct of the cell population is undergoing submerging in the $\mathrm{Pb}-2.2$ wt pct $\mathrm{Sb}$ alloy grown at $1.8 \mu \mathrm{m} \mathrm{s}^{-1}$. For the cell-to-dendrite transition morphologies, this interaction is manifested by the increased morphological ordering along the directional solidification length for the nearest and the second nearest neighbors (Figure 15(c)).

A unique range of primary spacing exists during directional solidification for the cellular morphologies. The ratio of the upper spacing limit (that containing the largest 10 pct) and the lower spacing limit (that containing the smallest $10 \mathrm{pct}$ ) is constant. Its value is $1.43 \pm 0.11$, as obtained from the nearest-neighbor spacing distribution, or $1.38 \pm$ 0.08 , as obtained from the MST branch-length distribution. Similar data for other alloys are lacking in the literature from where we can extract this ratio for steady-state growth of cellular arrays. Han and Trivedi ${ }^{[17]}$ have reported the 


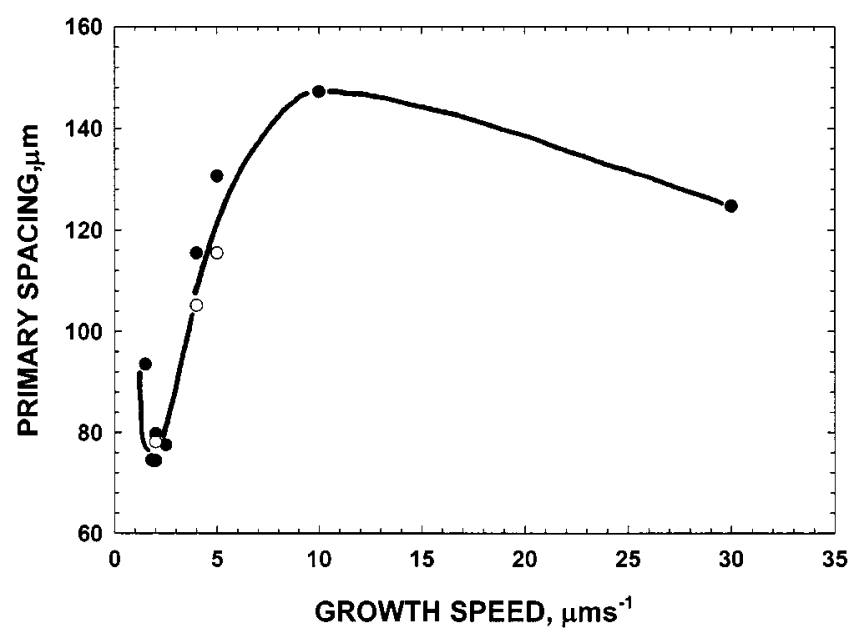

(a)

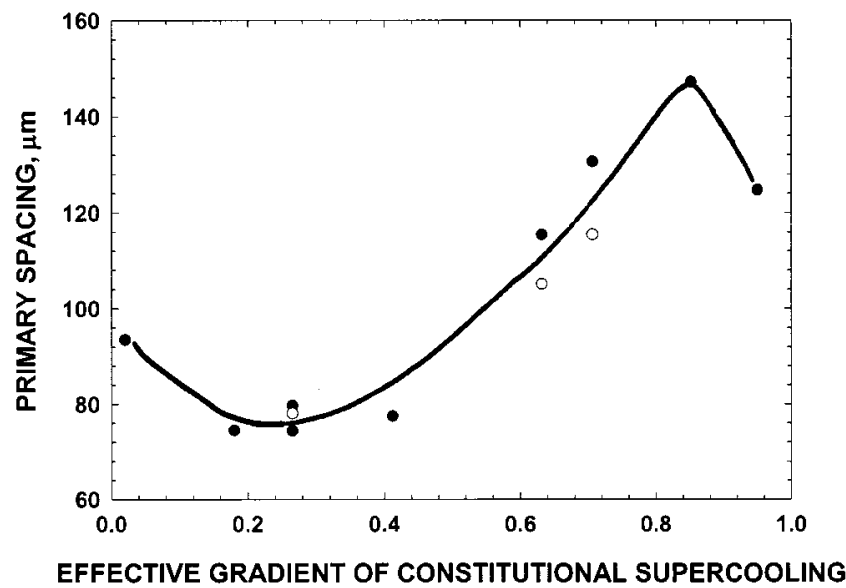

(b)

Fig. 13-Influence of increasing growth speed on the mean primary arm spacing (as measured by the Gaussian analysis of the nearest neighbor peak) of directionally solidified $\mathrm{Pb}-2.2 \mathrm{wt}$ pct. Sb alloy single-crystal samples grown along [100] at $164 \mathrm{~K} \mathrm{~cm}^{-1}$. Filled symbols correspond to the solidification distance of $10 \mathrm{~cm}$ before being quenched. The open symbols are for a growth of $3 \mathrm{~cm}$ before being quenched. (a) Mean primary spacing $v s$ growth speed. (b) Mean primary spacing $v s$ effective gradient of constitutional supercooling $\left[s^{*}=\left(1-D_{1} G k / V m_{1} C_{\mathrm{o}}(k-1)\right)\right]$.

minimum, mean, and maximum spacings observed during directional solidification of succinonitrile-acetone alloys. However, these experiments were conducted in thin-slab shaped cells to avoid convection and, therefore, do not provide large enough numbers to carry out meaningful Gaussian fit to the data. They observed the ratio of the maximum cell spacing to the minimum cell spacing to be 1.36, which is in reasonable agreement with 1.4 observed by us. Noel $e \mathrm{al}^{\left[{ }^{[4]}\right.}$ have presented similar data, a frequency distribution of equivalent diameter (diameter of the disk equal to the cross-section area of the cell) for directional solidification of succinonitrile-acetone alloy. These data yield the ratio of the upper and lower spacing limit to be 1.98 and 2.03 , very different from 1.4, observed in this study. The reason for this discrepancy is not clear. It may be because their experiments represent morphologies during initial transient and not during the steady-state growth of cellular arrays.

It is interesting to note that despite the very different
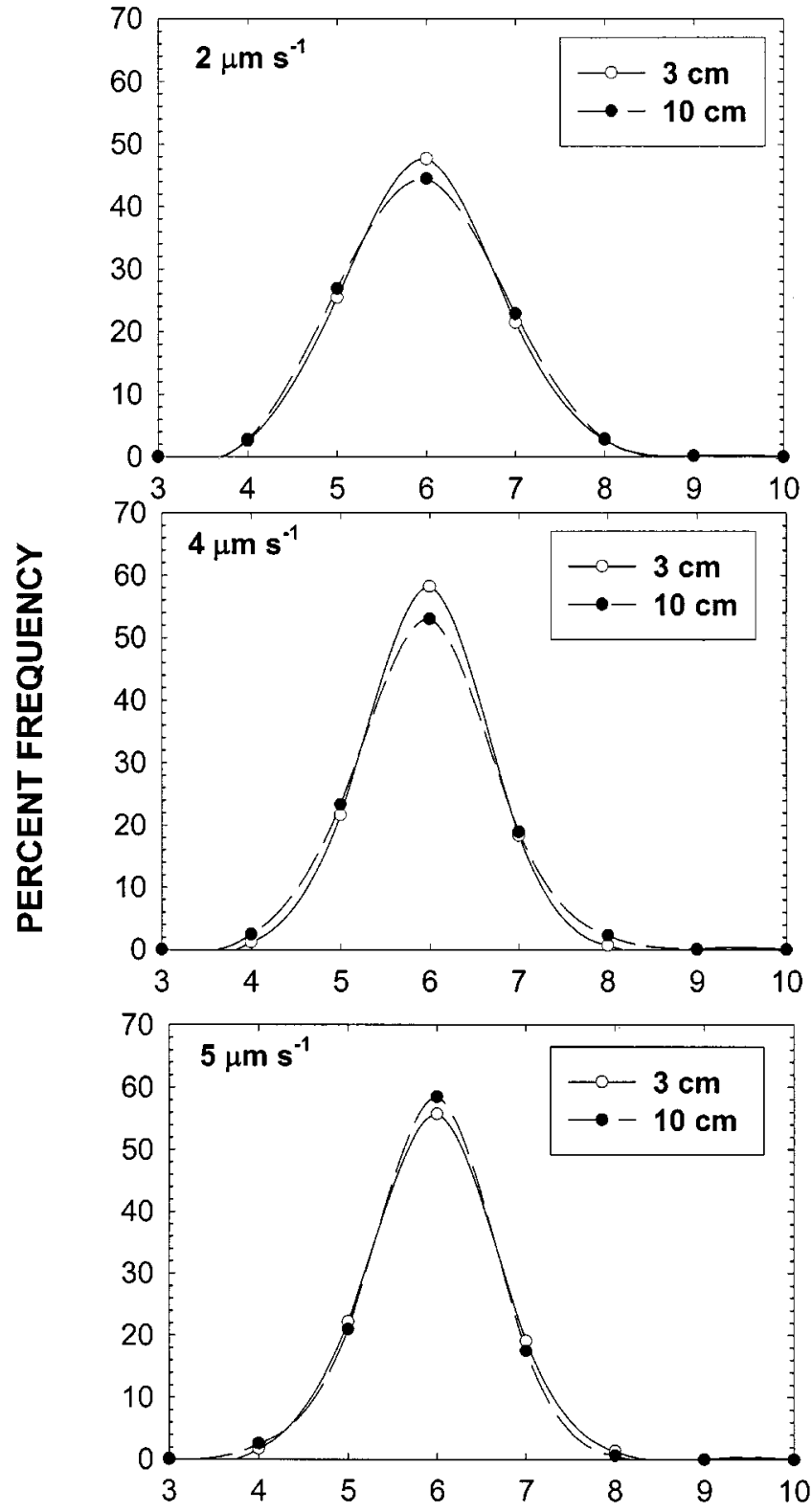

NUMBER OF NEAREST NEIGHBORS

Fig. 14-Frequency distribution of the number of nearest neighbors in samples, which are grown with shallow cell, deep cell, and cell-to-dendrite transition morphologies. Filled symbols correspond to the solidification distance of $10 \mathrm{~cm}$ before being quenched, and the open symbols are for a growth of $3 \mathrm{~cm}$ before being quenched. (a) Shallow cells grown at $2 \mu \mathrm{m}$ $\mathrm{s}^{-1}$. (b) Deep cells grown at $4 \mu \mathrm{m} \mathrm{s}^{-1}$. (c) Cell-to-dendrite transition grown at $5 \mu \mathrm{m} \mathrm{s}^{-1}$

nature and intensity of convection present during growth of the $\mathrm{Al}-\mathrm{Cu}$ and $\mathrm{Pb}-\mathrm{Sb}$ alloys almost all the observations about the two alloys are nearly identical for the cellular morphology. As described in section I, extensive natural convection is present during directional solidification of $\mathrm{Pb}-\mathrm{Sb}$ alloys because of the solutally, unstable growth condition. Whereas, only limited amount of convection caused by the presence of radial thermal gradient should exist during directional solidification of Al-Cu alloys, especially if one can reduce the extent of steepling, as is the case in the present study. Based on these experiments, it is not clear what role convection plays in determining the extent 


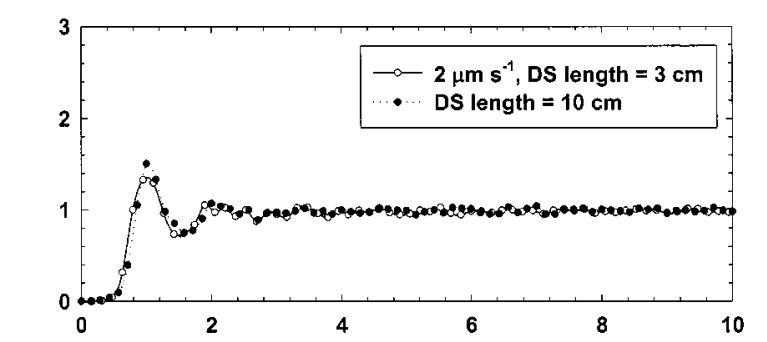

(a)

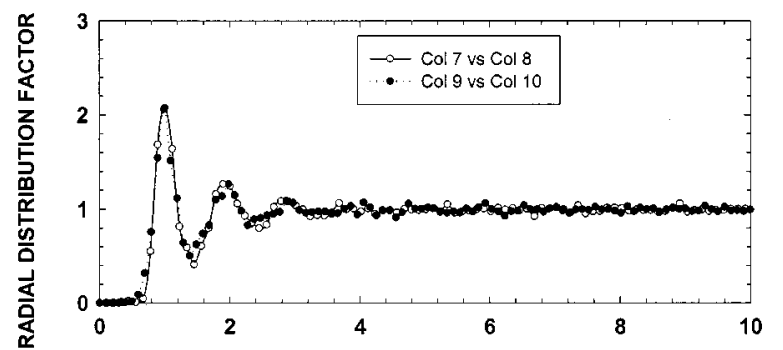

(b)

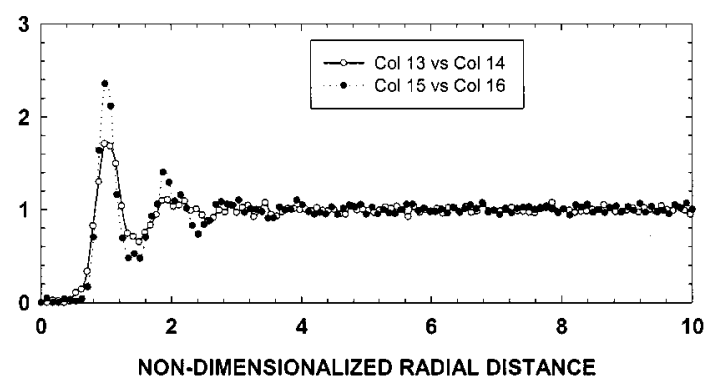

(c)

Fig. 15-Radial distribution factor for the $\mathrm{Pb}-\mathrm{Sb}$ alloy samples, which are grown with shallow cell, deep cell, and cell-to-dendrite transition morphologies. Filled symbols correspond to the solidification distance of $10 \mathrm{~cm}$ before being quenched, and the open symbols are for a growth of $3 \mathrm{~cm}$ before being quenched. (a) Shallow cells grown at $2 \mu \mathrm{m} \mathrm{s}^{-1}$. (b) Deep cells grown at $4 \mu \mathrm{m} \mathrm{s}^{-1}$. (c) Cell-to-dendrite transition grown at $5 \mu \mathrm{m} \mathrm{s}^{-1}$.

of scatter in the cellular arrangement or spacing distribution. This would require low-gravity directional solidification and quenching experiments under purely diffusive transport conditions. We plan to carry out such experiments in the near future.

\section{CONCLUSIONS}

A detailed statistical characterization of the observed cellular microstructures has been carried out in directionally solidified $\mathrm{Pb}-2.2 \mathrm{wt}$ pct $\mathrm{Sb}$ (thermal gradient of $164 \mathrm{~K} \mathrm{~cm}^{-1}$ ) and Al-4.1 wt pct Cu alloy single-crystal samples (thermal gradient of $110 \mathrm{~K} \mathrm{~cm}^{-1}$ ), which were grown along the [100] direction. The following conclusions can be drawn from this study.

1. Arrangement of cells as viewed on sections that are transverse to the growth direction, resembles the atomic arrangement of liquids. The FFT of the image containing the cell centers resembles the X-ray diffraction pattern of liquids, and the radial distribution factor for the cells is the same as the one expected for liquids.

2. An overall steady state, in terms of reaching a constant mean primary spacing, is achieved in about $3 \mathrm{~cm}$ of growth for the shallow cell, deep cell, and cell-to-dendrite morphologies. However, local rearrangements of the cells among their nearby neighbors continues throughout the growth process.

3. A unique range of primary spacing exists during directional solidification. The ratio of the upper and lower spacing limits, as defined by the largest 10 pct of the population and the smallest 10 pct of the population, is $143 \pm 0.11$

4. Extent of cell submerging decreases from about 14 pct for the shallow cells to nearly zero for the deep cells.

\section{ACKNOWLEDGMENTS}

This research was supported by the Microgravity Materials Research Program at NASA- Marshall Space Flight Center, Huntsville, Alabama.

\section{REFERENCES}

1. M.A. Eschelman, V. Seetharaman, and R. Trivedi: Acta Metall., 1988, vol. 36, pp. 1165-74.

2. B. Billia, H. Jamgotchian, and H. Nguyen Thi: Metall. Trans. A, 1991, vol. 22A, pp. 3041-50.

3. S.P. O'Dell, G.L. Ding, and S.N. Tewari: Metall. Mater. Trans. A, 1999, vol. 30A, pp. 2159-65.

4. N. Noel, H. Jamgotchian, and B. Billia: J. Cryst. Growth, 1997, vol. 181, pp. 117-32.

5. S.N. Ojha, G. Ding, Y. Lu, J. Reye, and S.N. Tewari: Metall. Mater. Trans. A, 1999, vol. 30A, pp. 2167-71.

6. R. Trivedi, H. Miyahara, P. Mazumder, and S.N. Tewari: unpublished research.

7. "HLIMAGE 97" Data Translation, Marlboro, MA.

8. "PeakFit," SPSS Incorporated, Chicago, IL.

9. "The Visualization Toolkit,"W. Schroeder, K. Martin, and B. Lorensen, Prentice-Hall PTR, Upper Saddle River, NJ, 1998, p. 398.

10. R.C. Prim: Bell System Techn. J., 1957, vol. 36, pp. 1389-1401.

11. C. Dussert, G. Rasigni, M. Rasigni, J. Palmari, and A. Llebaria: Phys. Rev., 1986, vol. 34 B, pp. 3528-29.

12. M.P. Allen and D.J. Tildesley: Computer Simulation of Liquids, Clarendon Press, Oxford, United Kingdom, 1987, p. 55.

13. L.H. Unger and R.A. Brown: Phys. Rev. B, 1985, vol. B31, pp. 5931-40.

14. J.D. Hunt and S.Z. Lu: Metall. Mater. Trans. A., 1996, vol. 27A, pp. 611-23.

15. K. Niwa, M. Shimoji, S. Kado, Y. Watanabe, and T. Yokokawa: Trans. AIME, 1957, vol. 209, pp. 96-101.

16. Metals Handbook, ASM, Metals Park, OH, 1973, vol. 8, p. 29.

17. S.H. Han and R. Trivedi: Acta Metall. Mater, 1994, vol. 42, pp. 25-41.

18. M. Li, T. Mori and H. Iwasaki: J. Mater. Sci. Lett., 1999, vol. 18, pp. 625-28. 